\title{
LA ARQUITECTURA TEXTIL
}

\author{
(TEXTILE ARCHITECTURE)
}

Juan Monjo Carrió, Doctor Arquitecto

Catedrático de Construcción de la

E.T.S. de Arquitectura de Valladolid

\section{RESUMEN}

Este trabajo estudia el uso de las telas en la Arquitectura cuando se emplean, no como meros complementos, sino como cubiertas $y$ cerramientos en general. Para ello, analiza, por una parte, la justificación funcional del uso de este tipo de material y, por otra, sus fundamentos tecnologicos, estudiando su tipologia morfológica con las distintas formas por apoyos y' cuelgues, y la tecnologia de diseño adecuada a sus caracteristicas, con descripción y estudio de la tela como material de construcción, sus caracteristicas mecánicas y fisicas, las soluciones de bordes y anclajes, etc. Por último, resume todos estos datos en un análisis del proceso de diseño, considerando la interacción entre la solución funcional, la solución formal y la solucion estructural.
$S U M M A R Y$

This work studies the use of cloths in Architecture, when they are used not as simple complements but as a whole of coverings and losures. To this purpose, it analyses, on one hand, the functional iustification of the use of such a material and on the other hand, its technological basis, studying its morphological type with the different shapes by means of supports and hangings and the uitable design technology according to their characteristics,

with description and study of the cloth as construction material, its mechanical and physical characteristics, making and setting up processes, type of joints, solutions for edges and anchorages, etc.

Finally, all these data are resumed in an analysis of the process of the design, regarding the interaction among the functional solution, the inrmal solution and the structural solution.

\section{Introducción}

Podria acuñarse este término (Arquitectura Textil) para designar a todas aquellas soluciones arquitectónicas (es decir, de definición y envoltura de espacios habitables) que utilizan como material principal de cerramiento la tela y en las que, como consecuencia, cobra importancia la «tecnologia textil» aplicada a la edificación. De hacerlo asi estariamos definiendo un tipo de Arquitectura muy actual que, aunque puedan encontrarse sus antecedentes en épocas muy remotas (incluso prehistóricas) y aunque en algunos aspectos se haya apoyado en soluciones tecnológicas de otros campos de la ciencia ya asentados, sin embargo, está todavía en un período de "observación», tanto por parte de técnicos como de profanos, aunque podemos asegurarle un futuro prometedor.

Naturalmente, podriamos entrar en la discusión de si una "simple tela" puede constituir Arquitectura en el sentido

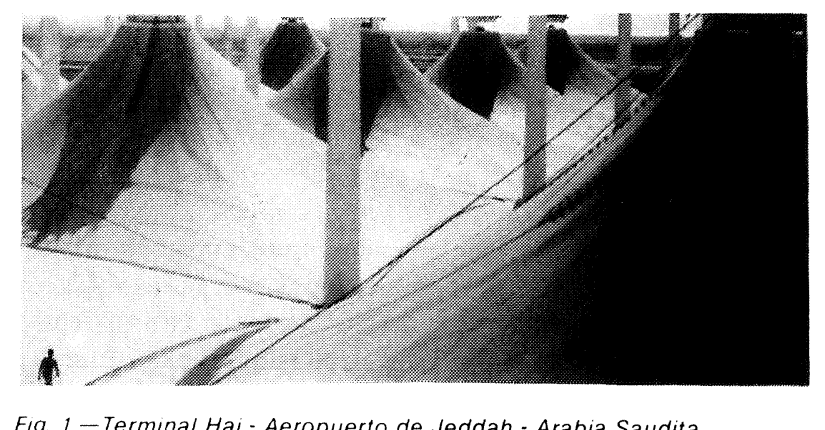

Fig. 1.-Terminal Haj-Aeropuerto de Jeddah - Arabia Saudita. tradicional de la palabra, cuando el uso principal, y casi exclusivo, que de ella se ha hecho en la edificación ha sido de mero complemento protector o decorativo. No obstante, desde el momento en que la tela no sea un simple complemento sino que constituya la estructura y la forma del edificio y cumpla las funciones principales del mismo, su categoría como material o elemento componente alcanza la de unidad constructiva e, incluso, la de sistema constructivo, y los resultados edilicios que con ella se obtengan pueden considerarse definitivamente como Arquitectura. De hecho en el mundo actual de la edificación con tecnología más avanzada, lo que se ha dado en llamar "estructuras de tela» son una posibilidad ampliamente aceptada para grandes proyectos, tan grandes como la terminal Haj del aeropuerto de Jeddah en Arabia Saudita (400.000 $\mathrm{m}^{2}$ cubiertos de tela), (Fig. 1).

En este sentido Host Berger opina que tanto la apertura de espacios, como la luminosidad, como, incluso, la calidad escultórica, suponen una "nueva Arquitectura» (nueva Arquitectura a la que proponemos llamar «Arquitectura textil»).

Esta nueva Arquitectura tiene evidentemente unas características que la diferencian y que no se basan sólo en su tecnología (material, técnicas textiles, etc.) sino que afectan tanto a su concepción desde la fase de proyecto como a su aspecto formal y compositivo y, sobre todo, a su aspecto funcional, ya que el espacio que encierran tiene, o puede tener, unas características especiales. En efecto, desde el punto de vista tecnológico el tipo de material y sus capacidades mecánicas son absolutamente 
nuevas, con un aprovechamiento máximo con respecto a su peso y a su costo, y exigen, por tanto, un enfoque nuevo, permitiendo la cobertura de grandes espacios con enorme facilidad. Por otra parte, su aspecto formal rompe con los cánones clásicos y tradicionales de la Arquitectura, apareciendo diseños más orgánicos, consecuentes con la tecnologia propia y las necesidades funcionales. Por último, el espacio definido tiene unas características especificas, de mayor claridad y flexibilidad, aunque también de ciertas limitaciones exigenciales, pero que en su conjunto constituye lo que Host Berger denomina un «mega espacio» o, incluso, «espacio mejorado». En definitiva podríamos decir que la Arquitectura textil está en el límite de la cruda expresión de la naturaleza y consigue ambientes habitables con el minimo de materiales $y$, por tanto, de coste de ejecución.

Para su estudio, aunque sea de un modo esquemático, pero suficiente para tener una primera perspectiva de los logros que se pueden alcanzar con este tipo de soluciones, las dividiremos en dos grandes grupos que corresponden básicamente a dos aproximaciones técnicas al problema y que tienen como origen dos vías distintas tanto histórica, como tecnológica, como formales. Asi pues hablaremos de telas colgadas y de telas hinchadas.

\section{Estructuras de telas colgadas}

Son en su origen las más antiguas, pues su base la podemos encontrar en los pueblos nómadas y guerreros de los albores de la historia, con una continuidad de uso que llega, incluso, hasta nuestros días, siempre que exista este carácter de provisionalidad y movilidad como el que sigue imperando en algunos pueblos árabes del desierto o, incluso en nuestras civilizaciones, en los grupos de atracciones circenses cuyo espectáculo se alberga en carpas de diversas dimensiones y formas pero con la tela como denominador común.

En un principio fueron las pieles las que constituyeron las membranas que cerraban los espacios habitables, apoyadas sobre entramados leñosos. Más adelante, cuando apareció el tejido, éste sustituyó a la piel como membrana más flexible, de mayor tamaño y de formas y colores más variados, perdurando de ese modo, y sin ninguna aportación técnica destacable, hasta la época moderna, variando exclusivamente su tamaño o los materiales de la estructura portante. La Arquitectura ha tenido que esperar hasta este siglo para aceptar este material y esta tecnología en su campo, gracias, entre otras cosas, a la aparición de las fibras sintéticas que han permitido conferir a las telas unas capacidades fisicas y quimicas de evidente interés. De ese modo, con telas más resistentes y más duraderas, se ha podido pensar en su uso para grandes cubiertas con soluciones que, aunque sigan conservando su aire de provisionalidad, incorporan una posibilidad de permanencia hasta entonces inusitada.

Podemos fijar la década de los años 60 como la que marca la irrupción de estas soluciones en telas colgadas en la Arquitectura Europea, de la mano, en gran medida, del alemán Frei Otto, mientras que en los Estados Unidos (por citar los países pioneros en estos campos) su apari-

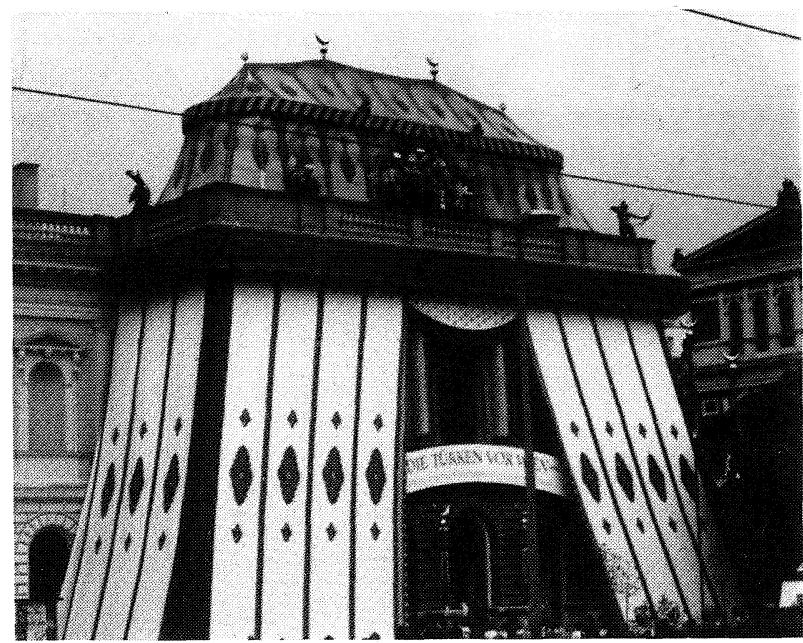

Fig 2

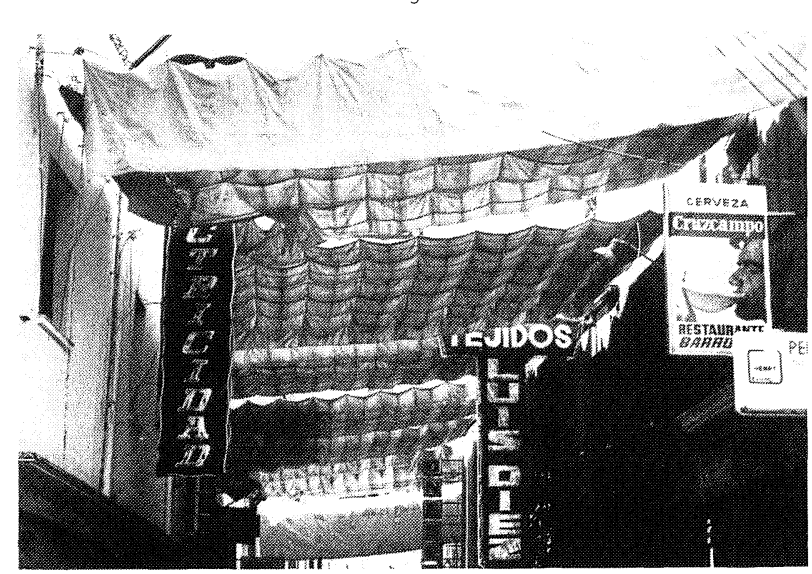

Fig. 3.-Toldos en Sevilla.

ción se retrasa algo, hasta comienzos de los setenta en que se monta la "tienda" del colegio La Verne en California.

Hasta estos momentos la Arquitectura debe agradecer, no tanto la actuación de los técnicos (aunque sí de los científicos del mundo textil y del de la quimica de los plásticos) como la popular, en dos claras líneas de soluciones funcionales y vernáculas que han mantenido vivo el espíritu del uso de este tipo de soluciones textiles por sus verdaderas posibilidades funcionales, a pesar de la pobreza de la tecnologia.

Por un lado, los «artistas trashumantes» que han seguido manteniendo sus carpas circenses a pesar de los continuados problemas de seguridad que llevaban consigo, y que pueden considerarse los verdaderos precursores de las grandes estructuras de telas colgadas actuales (Fig. 2). Por otro, las soluciones populares de los pobladores de las regiones cálidas, y no me refiero sólamente a los pueblos nómadas de los desiertos, sino también a los habitantes de las cuencas mediterráneas que han sabido diversificar el uso de las velas de sus barcos convirtiéndolos en toldos de sus viviendas, calles y plazas, improvisados primero y premeditados y más permanentes después (Fig. 3). 
También los militares han jugado su papel de conservadores y transmisores de una tradición de antiguo en los pueblos guerreros, usando tiendas de campaña que cumplian perfectamente su misión funcional y de provisionalidad.

A todos ellos, en conjunto, debemos la tradición del uso de la tela en nuestros edificios, con un carácter complementario primero (toldos) y con un carácter integral después; tradición que ha podido completarse con la nueva tecnologia textil para dar como fruto esta "Arquitectura textil» de grandes cubiertas con telas colgadas.

\subsection{Justificación funcional}

Todo ese proceso histórico, y el complemento tecnológico actual, nos pueden facilitar el análisis del interés real de su uso en nuevas soluciones, sin el cual todas las justificaciones tecnológicas huelgan.

Destaca, en primer lugar, la posibilidad de cubrir y cerrar grandes espacios a un coste relativamente reducido y con una gran rapidez de ejecución. En efecto, la capacidad estructural de la tela (que veremos en los apartados siguientes) y su reducido peso $\left(\leq 1 \mathrm{~kg} / \mathrm{m}^{2}\right)$ hacen que se puedan resolver fácilmente grandes luces con un costo mínimo de estructura soporte, además del propio de la tela. El precio de las grandes cubiertas construidas recientemente, incluida la estructura soporte, oscila entre las 10.000 y las $30.000 \mathrm{pts} / \mathrm{m}^{2}$ según su magnitud dimensional (de 10 a 30 m de luz libre). En cuanto a la rapidez de ejecución, ésta es evidente desde el momento en que la tela puede considerarse como una membrana continua prefabricada, que viene totalmente "confeccionada» de taller y que, por tanto, en obra no requiere más que la ejecución de la estructura soporte y la sujeción de la tela a la misma.

Por otra parte, debemos considerar la permanencia del carácter de temporalidad en estas soluciones textiles, a pesar de las características resistentes de las nuevas telas. En efecto, el hecho de su carácter de membranas prefabricadas hace posible su fácil montaje y desmontaje y, por tanto, su reutilización. De hecho, esa sigue siendo la característica fundamental en las grandes carpas de los circos, y puede ser un aspecto que marque carácter a muchas de estas soluciones cuando su uso no sea temporal, como puede ser el caso de cubiertas de mercados públicos, grandes toldos de piscinas, etc. En todo caso, si una tela tiene que ser de "quita y pon» sus características fisicas deberán contemplar el continuo plegado y desplegado que, como veremos, puede ser un factor condicionante desde el punto de vista de su confección.

Para su funcionalidad es importante también el carácter del ambiente que queda encerrado por la tela, sobre todo si ésta constituye lo que llamaremos una solución integral. En efecto, como "cerramiento", la tela es un material relativamente pobre ya que, por su poco cuerpo, no constituye un buen aislamiento. Sin embargo, en contraposición, permite un mejor contacto con el entorno exterior (sobre todo luminoso) cuando ello es interesante. Analicemos estos aspectos:
Por un lado, la transmisión luminosa de las telas variará según el tipo de tejido y el de recubrimiento, tal como veremos más adelante, ofreciendo una gama que va desde una transmisión pequeña de luz para las más opacas, del orden del $10 \%$, hasta una gran transmisión para las más claras, del orden del $50 \%$. Vemos, pues, que el ambiente luminoso debajo de estas cubiertas puede satisfacer grandes necesidades de iluminación, llegando incluso a producir una oscuridad total con el uso de telas opacas.

Por otra parte, su aislamiento térmico es muy pobre, ya que tiene una masa y un espesor muy reducidos $(\leq 1 \mathrm{~mm}$ de sección) por lo que no serán útiles cuando necesitemos una gran protección térmica. Sin embargo podemos suplir este teórico defecto mediante el diseño, tratando de aprovechar las energias naturales a nuestra conveniencia. Asi, en invierno, tenderemos a buscar el efecto invernadero gracias a la gran transmisión de la energia solar apuntada (Fig. 4). Si mantenemos el aire interior en reposo, la tela nos ayudará a captar energia calorifica del exterior, tanto de la radiación solar directa como de la difusa, consiguiendo un aumento interior de la temperatura que puede llegar a ser suficiente.

Siguiendo un procedimiento similar, aunque inverso, podremos trabajar en verano, buscando el efecto sombrilla. Bastará, simplemente, que evitemos la radiación directa gracias a la tela (disminuyendo en lo posible la transmisión de radiación a través) y establezcamos corrientes naturales de aire debajo de la misma, preferentemente ascendentes, con objeto de que exista una renovación continua que baje la temperatura interior (Fig. 5). Como un ejemplo podemos indicar que bajo la mencionada cubierta del aeropuerto Haj en Jeddah (Arabia Saudita), en pleno desierto, se consiguen temperaturas de $24{ }^{\circ} \mathrm{C}$, gracias al diseño de las «tiendas» de la cubierta que producen una continua circulación de aire.

En definitiva, y como veremos más adelante, el uso de estas soluciones tiene que ir acompañado de un correcto diseño que haga no sólo un óptimo aprovechamiento estructural de la tela con fines económicos, sino además un

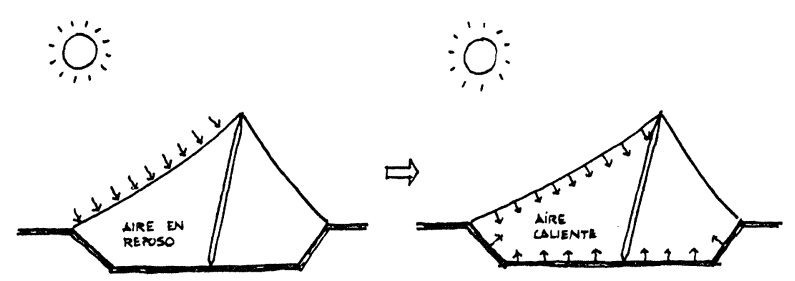

Fig. 4.-Efecto invernadero.
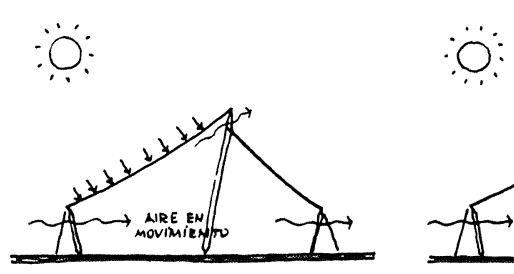

Fig. 5.-Efecto sombrilla. 
correcto funcionamiento de la solución a efectos de un uso óptimo y una forma final adecuada al entorno.

En cualquier caso, y como colofón de su funcionalidad, podemos distinguir dos tipos de usos para estas soluciones textiles. Las que consideran el uso integral de las telas para la solución arquitectónica de que se trate (arquitectura textil global) quizás la más interesante, y las que consideran estas soluciones como un complemento del diseño y función del edificio (arquitectura textil complementaria), con seguridad la más extendida y asequible en la actualidad que, aunque necesaria y útil ahora y siempre, no debe limitar nuestro horizonte de uso.

\subsection{Fundamentos tecnológicos}

La utilización de la tela en la edificación, como la de cualquier otro material, parte de la base, por un lado, de su integridad física y, por otro, de su funcionalidad ante las exigencias del usuario y del medio.

La integridad fisica, a su vez, exige su estabilidad mecánica, máxime cuando el material tiene además una misión estructural. En el caso de la tela, por ser éste un material flexible (una membrana, en su conjunto) se logra esa estabilidad gracias a la tensión. Es decir, sólo sometiendo a la tela a una tensión de tracción en, por lo menos, dos direcciones cruzadas, le daremos la estabilidad necesaria para que pueda cumplir el resto de sus funciones. Aunque este hecho es evidente, pues basta comprobarlo en cualquier trozo de tela que tengamos a mano en el que, hasta que no lo sometamos a tracción en varias direcciones, no lograremos eliminarle las arrugas y darle, por tanto, estabilidad, sin embargo conviene analizarlo brevemente. Para ello pensemos en el comportamiento mecánico de un cable. Si lo colgamos en un extremo, obtendremos una linea recta vertical que resulta inestable ante cualquier esfuerzo horizontal, ya que tiende a desplazarlo de su situación, a menos que lo atirantemos desde el extremo inferior. Lo mismo ocurre si colgamos el cable entre dos puntos. Por su peso propio tenderá a adquirir la forma de una catenaria, más tendida cuanto mayor sea la tensión en sus extremos y menor sea el peso propio (Fig. 6). No obstante, el cable sólo, aunque esté tensado en sus extremos, sigue siendo inestable ante esfuerzos perpendiculares, sobre todo si lo son al plano vertical que contiene la catenaria, pudiendo desplazarse del mismo o, incluso, entrar en vibración y deformarse dentro de este plano. Para estabilizarlo, no basta, pues, introducirle una tensión contraria en el mismo plano, sino que habrá que tensarlo según algún plano cruzado (preferentemente perpendicular) con el primero. Aparece asi un segundo orden de cables con tensión inversa ( $\mathrm{si}$ la primera es hacia arriba ésta será hacia abajo y viceversa) que, de tratarse de una cubierta de un espacio y contar con un conjunto de cables paralelos, deberemos establecer dos "familias" de cables, la del primer orden, colgados y la del segundo orden o estabilizadores, con tensión inversa (Fig. 7).

En su conjunto habremos llegado a una malla de cables tal que en cualquier punto de cruce de la misma, los cables tienen tensiones contrarias. Si trasladamos esta si-

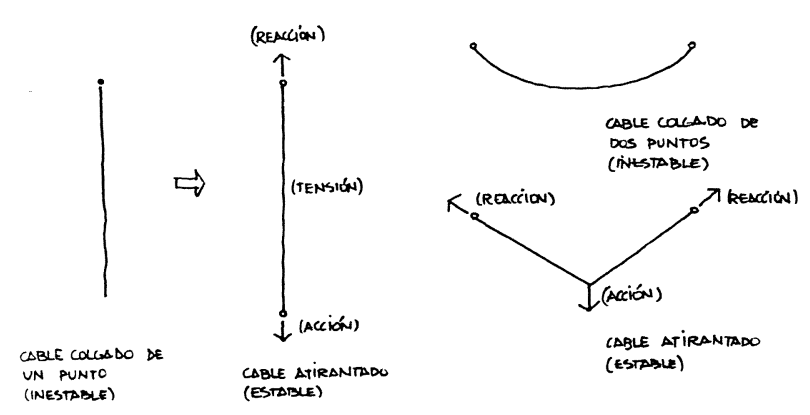

Fig. 6.-Estabilidad en cables.

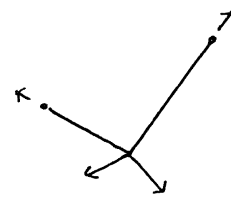

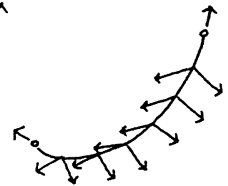

ESTABILIZACION EN PLANO PERPENDICULAR FAMILIS DE CAOLES EsTABILIZZADORES

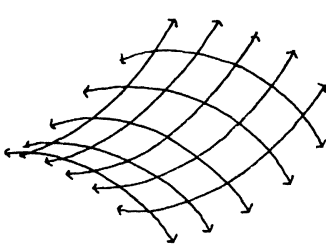

DOBLE FAMIULA de carles.
Fig. 7.-Familias de cables.

tuación a una tela (que es, en realidad, una malla tupida y prefabricada de cables textiles) comprenderemos perfectamente su sistema de estabilización y, por tanto, la necesidad de la doble tensión (tensión en dos direcciones) para conseguir su estabilidad.

La introducción de esta doble tensión en las solucines actuales de la arquitectura textil es dual y marca la división entre los dos grandes tipos enunciados (telas colgadas y telas hichadas). Centrémonos ahora en las telas colgadas. En ellas la tensión se introduce despreciando su peso propio (que es prácticamente despreciable, $\leq 1 \mathrm{~kg} / \mathrm{m}^{2}$ ) y sometiendo sus extremos a una tensión directa. Si la tensión está en una sola dirección, aunque en dos sentidos, sólo tensaremos, por así decir, una de las supuestas familias de cables, y aparecerán "arrugas» en esta dirección. Para evitarlas deberemos introducir tensión en la otra dirección (en la otra familia de cables). Sin embargo, si esto lo realizamos dentro de un plano, el resultado es una tela plana, tensada, pero inestable ante cualquier esfuerzo perpendicular, no tanto su peso propio, que como vimos es muy pequeño, cuanto las cargas del tipo de la nieve o del viento. Para introducir una estabilidad definitiva, deberemos salirnos del plano, de un modo similar a como veiamos en las familias de cables, y conseguir que la tela quede en forma de superficie "anticlástica» de tal modo que en cualquier punto de la misma existan dos curvaturas de sentidos opuestos, producidas por tensiones cruzadas y en estos mismos sentidos. Este será el único modo de conseguir una estabilidad total.

El diseño funcional y los esfuerzos mecánicos que se puedan prever, nos dará la superficie formal adecuada en cada caso. Sólo bastará utilizar el tejido que resista tanto las tensiones previas como las que resultan al aparecer las cargas exteriores, básicamente nieve y, sobre todo, viento. Más adelante veremos estos extremos. 


\subsection{Tipología morfológica}

Los aspectos del apartado anterior condicionan en cierta medida la forma de la cubierta textil. Si a ello unimos las condicionantes funcionales y las del entorno, obtendremos la forma más adecuada de la arquitectura textil para cada caso. Para ello, analicemos los principales grupos de formas que nos aparecen considerando los dos primeros aspectos (técnicos y funcionales) para de entre ellos escoger las que mejor se adecúen a la morfología ambiental de cada caso.

Podemos distinguir tres grandes grupos que nos darán, a su vez, otros subgrupos, y que constituirán las tipologías simples iniciales. A partir de ellas buscaremos las soluciones, que podrán llegar a ser combinaciones de éstas.

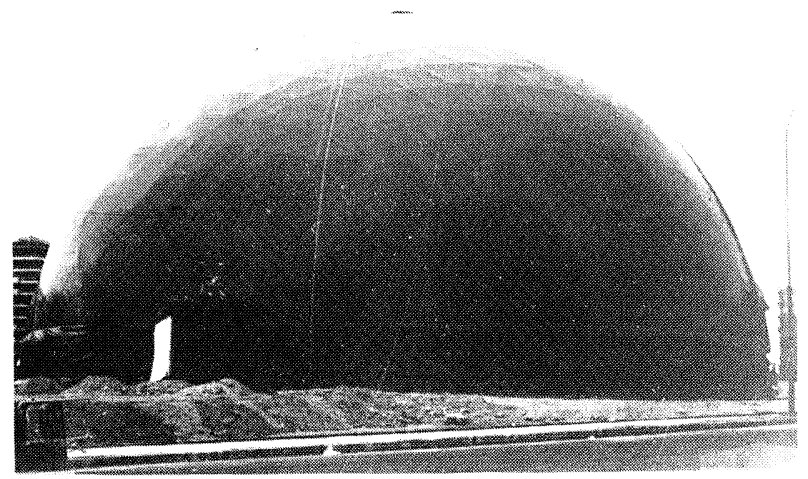

Fig. 8. - Tela apoyada sobre entramado geodesico.

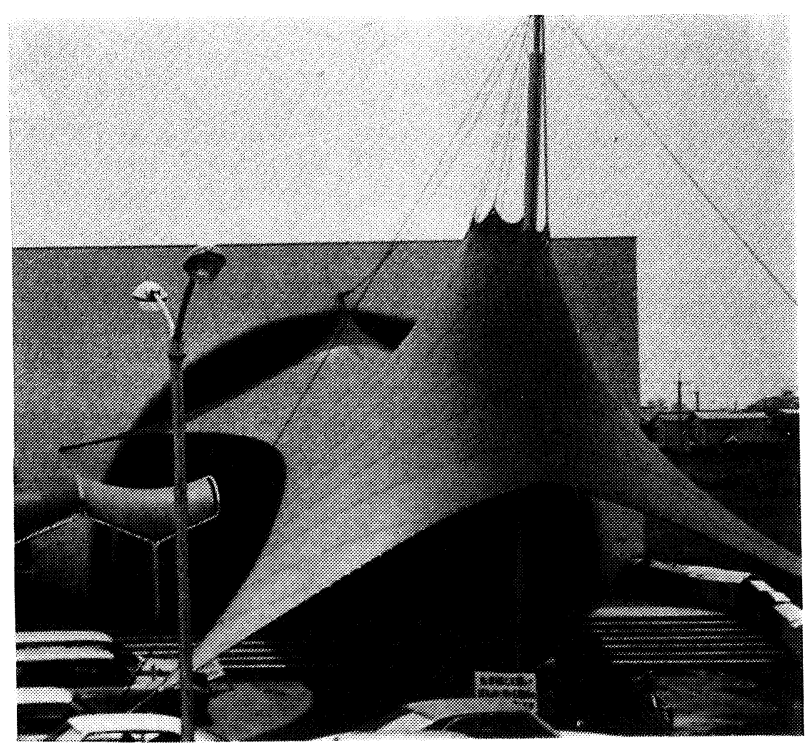

Apoyo simple interior.

Fig. 10.

Apoyo doble interior

\subsubsection{Telas apoyadas}

La tela simplemente "se deja caer" sobre un entramado estructural lo suficientemente tupido como para evitar tensiones en ella. La tela actúa sólo como cerramiento y no se aprovecha su capacidad tensional. Se infrautiliza.

Son las soluciones más antiguas que todavia están en vigor en muchos casos, bien por desconocimiento de sus posibilidades, bien por la calidad de la tela asequible, bien por necesidades funcionales o formales especificas. Se obtienen en estos casos, por lo general, superficies sinclásticas en las que resulta evidente la ausencia de tensión en la tela (Fig. 8).

\subsubsection{Telas colgadas por puntos}

Se establecen unos puntos de apoyo elevados, desde donde se cuelgan las telas anclándolas en otros puntos más bajos.

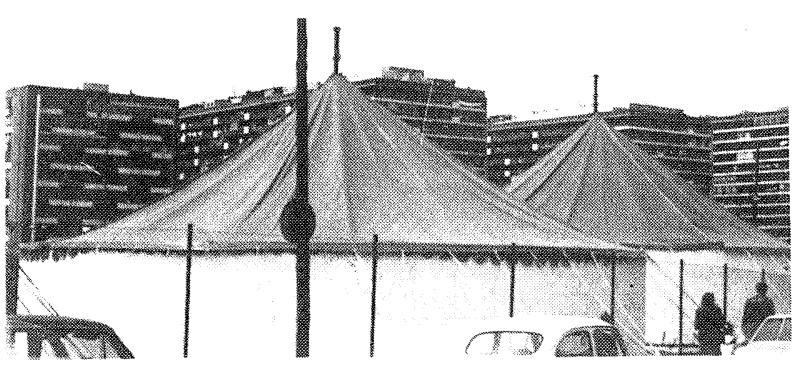

Fig. 9.-Tela suelta
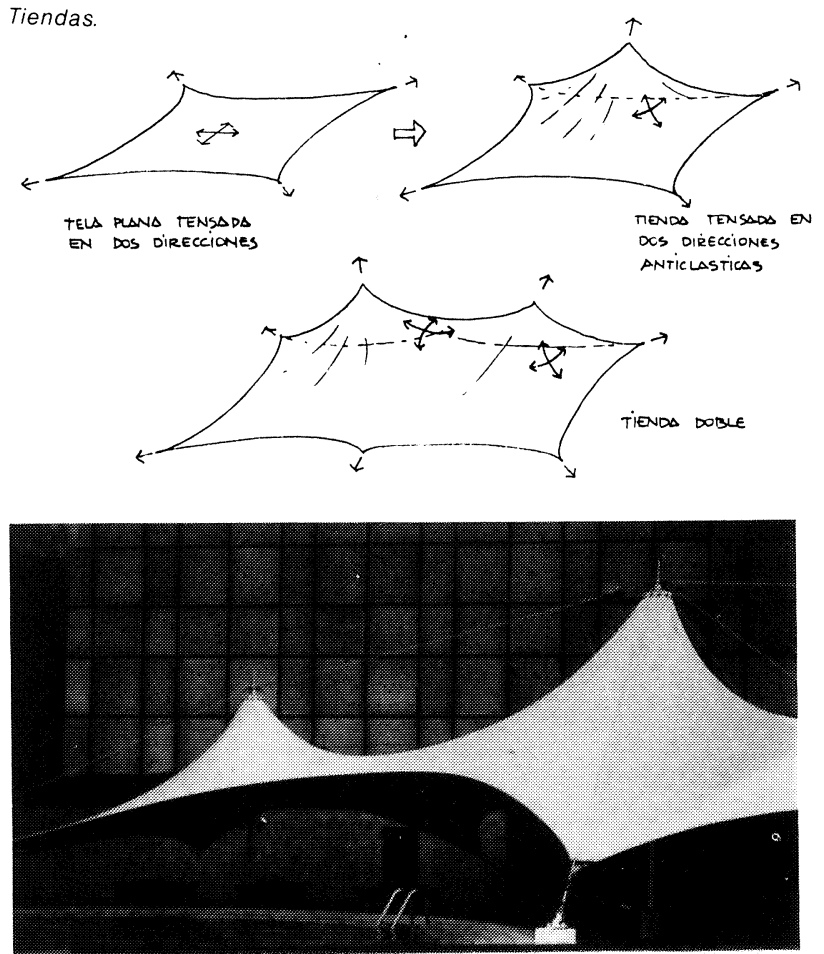
También en este caso cabe el simple "cuelgue» sin ningún tipo de tensión en la tela (Fig. 9). La solución pierde interés, tanto por la infrautilización de la tela, como por la ausencia de formas armoniosas, como, incluso, por la deficiencia de su actuación ante esfuerzos de viento.

Si introducimos, sin embargo, las tensiones adecuadas para la estabilización de la tela, podemos distinguir entre las soluciones en los que los apoyos elevados están en el interior de la superficie textil y aquellos que están en el exterior.

\subsubsection{Apoyos puntuales interiores}

Los apoyos se logran bien mediante estructuras inferiores (mástiles) bien a base de estructuras exteriores a la tela tipo grúa. En cualquier caso podemos estudiar su génesis y los tipos más importantes a partir de un sencillo ejemplo.

Si partimos de una superficie textil rectangular plana tensada, podemos aumentar su estabilidad elevando un punto intermedio (Fig. 10). Tendríamos una solución «en tienda" de un solo apoyo. Si la superficie total es muy grande, para conseguir la curvatura necesaria tendriamos que elevar excesivamente el punto de apoyo, lo que encareceria la solución. Entonces podemos elevar dos puntos, obteniendo una forma de "tienda doble», de diversas posibilidades formales según alturas y posiciones relativas de los apoyos.
En ambos casos, el anclaje hacia abajo está en el perímetro de la superficie, bien sea por puntos, bien por línea continua, según si necesitamos un toldo abierto, o queremos una solución integral que cierre completa o parcialmente el espacio.

Si por necesidades funcionales y estructurales, necesitamos elevar tres o más puntos de una misma tela, empiezan a aparecer puntos centrales con superficies sinclásticas convexas hacia arriba, que no sólo pierden la estabilidad de la tela sino que, además, resultan puntos de acumulación de agua, nieve, suciedad, etc. La solución consistirá en establecer anclajes centrales en estos puntos, lo que nos dará formas de «tiendas invertidas» en ellos (Fig. 11) y nos permitirá eyacuar las posibles acumulaciones antes mencionadas.

En cualquiera de estas soluciones y cualquiera que sea el perimetro de la superficie cubierta en planta, se puede y debe conseguir que la tela, en todos sus puntos, tenga doble curvatura opuesta y forme, por tanto, una superficie anticlástica.

\subsubsection{Apoyos perimetrales exteriores}

Para superficies de cubierta más pequeña y, sobre todo, cuando no necesitamos cerramientos laterales, podemos ir a elevar, por puntos, el borde de la superficie textil. Si partimos, por ejemplo, de un rectángulo y elevamos uno de sus ángulos, nos aparece el típico paraboloide hiperbólico o "silla de montar» y nos bastará anclar los otros

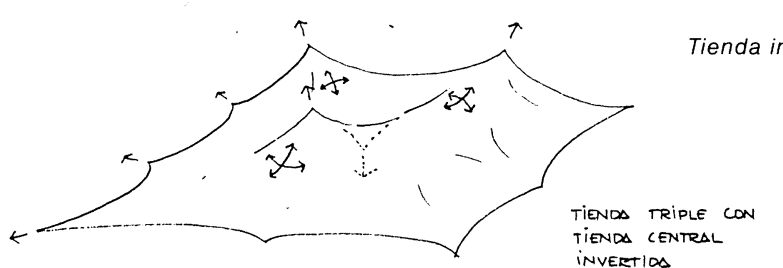

INVERTIOS

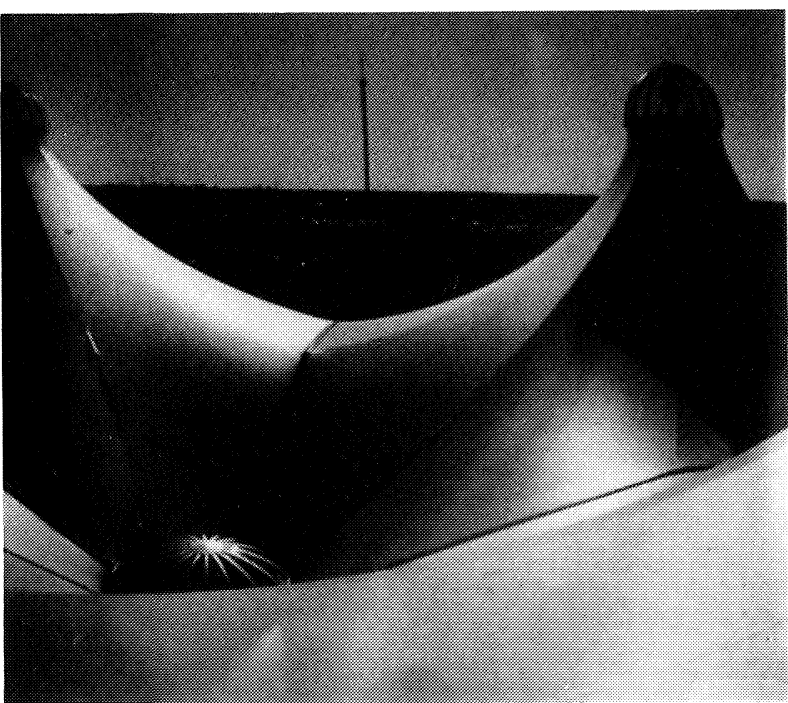

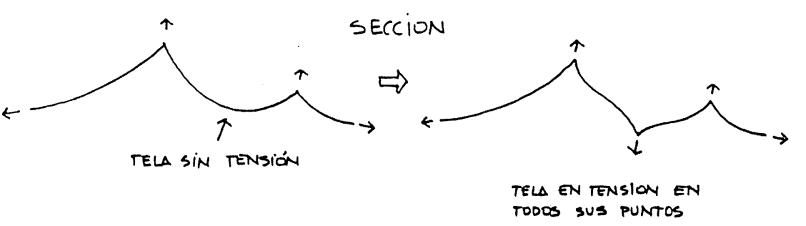

TODOS SUS PUNTOS

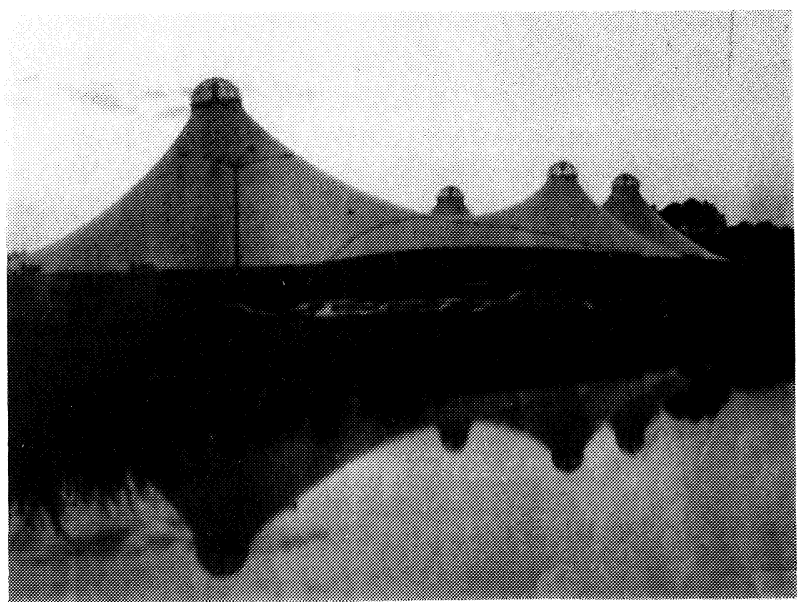

Fig. 11.-Cuatro apoyos interiores con tienda invertida en el centro. 
tres puntos para asegurar la tensión bidireccional en toda la superficie (Fig. 12). Por muy complicada que sea la planta que debemos cubrir, podemos llegar a esta solución y obtener un sinfin de formas finales sin más que ir variando las alturas de los puntos de anclaje y su situación.

Por último, no resulta nada difícil comprender la posibilidad de combinación de ambos tipos de apoyos (interiores y exteriores) y deducir la infinidad de formas que se pueden obtener de una misma planta y superficie de cubierta.

\subsubsection{Telas colgadas por lineas}

Las mismas operaciones que hemos hecho con los apoyos puntuales podemos repetirlas con apoyos lineales, desde el simple cuelgue de la tela desde una linea recta o curva, hasta su tensión en los mismos términos.

Si nos limitamos a «dejarla caer» volvemos a soluciones faltas de aprovechamiento, tanto estético como estructural, y poco estables ante los agentes exteriores. Si, por el contrario, sometemos la tela a tensión buscando la doble curvatura inversa (anticlástica) alcanzamos de nuevo dos tipos de soluciones.

\subsubsection{Apoyos lineales interiores}

De nuevo necesitamos una estructura auxiliar de apoỵo, bien situada debajo de la tela, recibiendo su apoyo, bien exterior a la misma, de la que cuelga la cubierta textil. En estos casos, además, cabe distinguir entre apoyos lineales rectos y apoyos lineales curvos o quebrados, que nos ofrecen mayor posibilidad de alcanzar superficies anticlásticas, dependiendo siempre del anclaje perimetral inferior.

Si seguimos con el ejemplo iniciado en 2.3.2.1, supuesta una tela tensada plana, podemos aumentar su estabilidad elevando una línea interior que producirá un efecto tienda con dintel de apoyo (Fig. 13); la misma "tienda» nos aparecerá si en lugar de dintel la línea de apoyo tiene forma de arco, siempre que el perímetro siga anclado. Sin embargo, si la línea de apoyo atraviesa toda la tela, el tipo de superficie que nos aparece será distinta si el apoyo es recto o curvo. En el primer caso (dintel) la lesión aparece sólo en una dirección, lo que produce inevitables arrugas (Fig. 14), mientras que en el segundo (arco) conseguimos la superficie sinclástica y, por tanto, la estabilidad total de la tela con ausencia de arrugas.

Si ahora modificamos sensiblemente el apoyo lineal que nos producía arrugas de tal manera que evitemos que las dos líneas rectas de apoyo de los extremos de un mismo trozo la tela está en un mismo plano, vuelve a parecernos un paraboloide hiperbólico como ocurría en 2.3.2.2. y
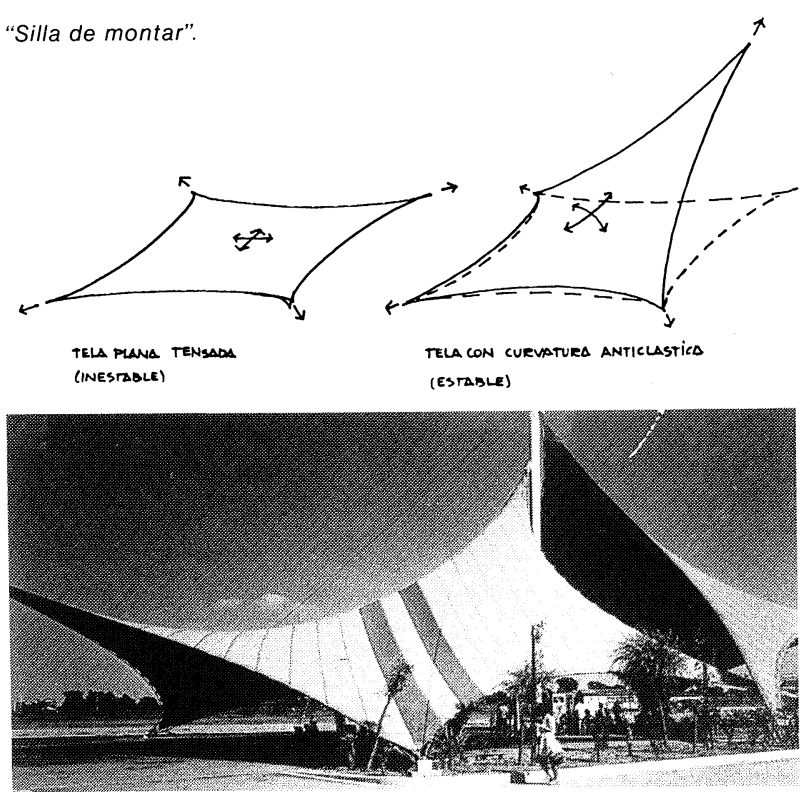

Fig. 12.-Apoyos exteriores múltiples.

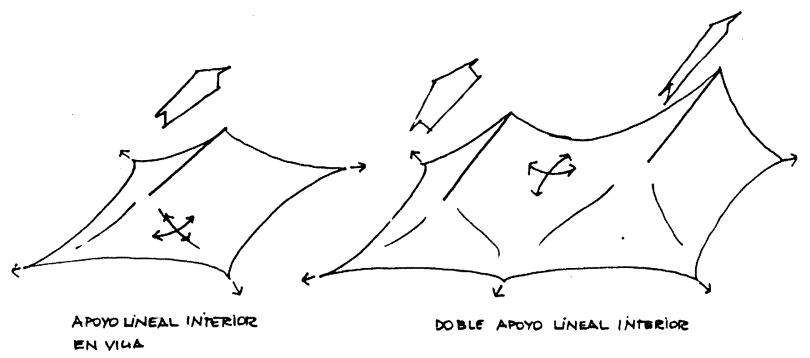

Fig. 13.-Tiendas lineales.

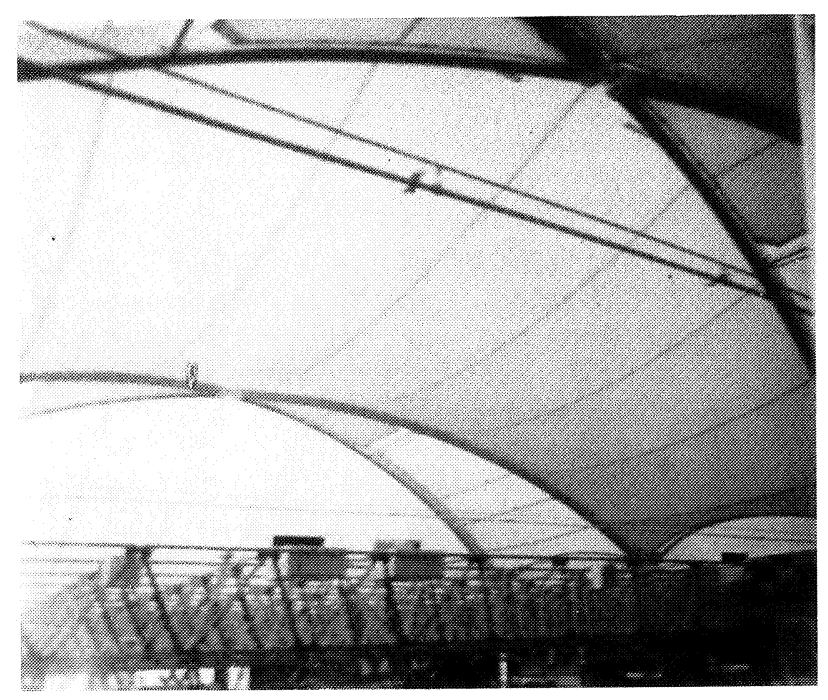

Apoyos lineales interiores en arco.

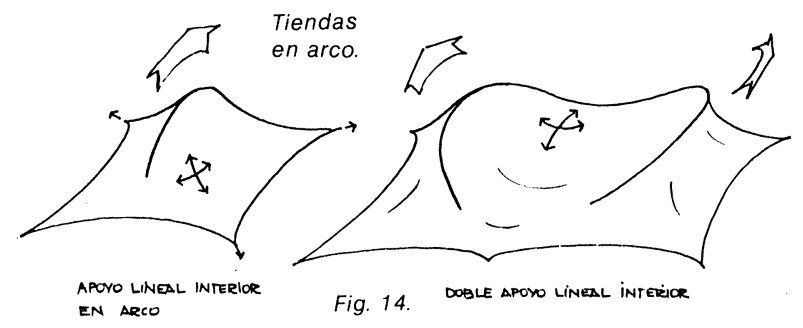




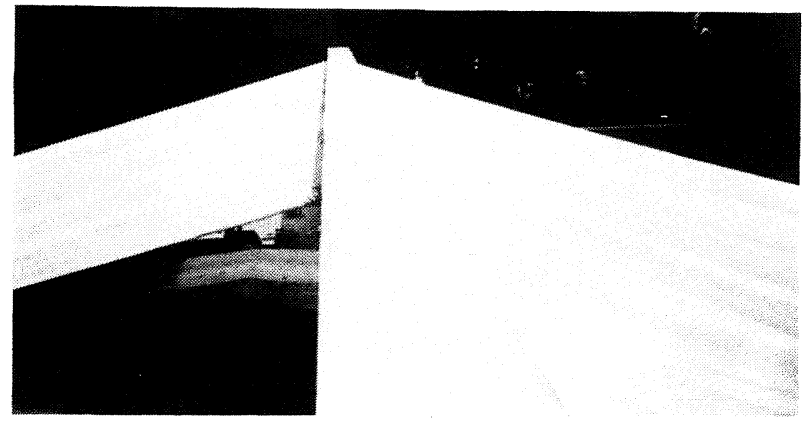

Superticie cilındrica arrugada

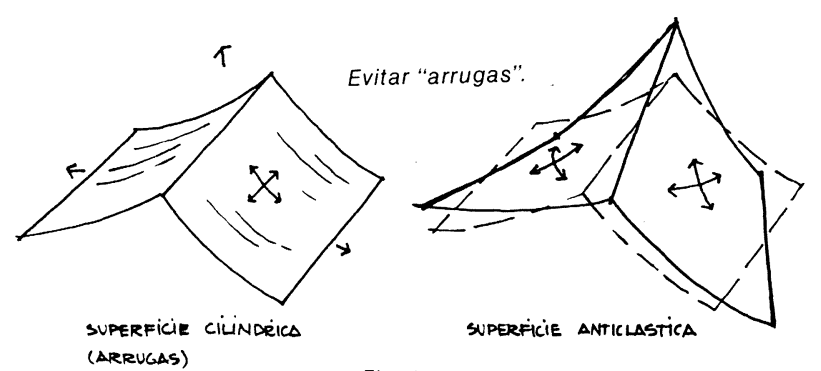

Fig. 15.

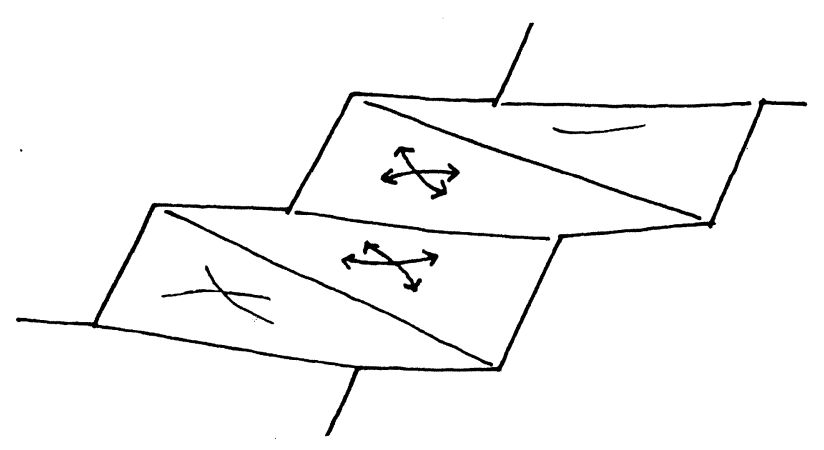

Fig. 16.-Superficie quebrada (anticlástica).

desaparecen, por tanto, las arrugas (Fig. 15). Ello nos da idea de que otro modo de obtener la doble tensión con apoyos lineales rectos es «quebrándolos». Es decir, cualquier apoyo lineal quebrado nos permite solucionar de nuevo la estabilidad de la tela.

\subsubsection{Apoyos lineales exteriores}

Estos comentarios del apartado anterior nos dan idea de cuál será la solución adecuada para cuando nuestros apoyos lineales están en el perímetro de la cubierta textil.

La necesidad de este nuevo grupo de soluciones nos aparecerá, cuando, sobre todo, necesitemos una cubierta cerrada, es decir, con continuidad con el resto del edificio. Entonces deberemos procurar que las líneas perimetrales de la cubierta, o bien sean curvas, o bien lineas quebradas y, en cualquier caso, a distintas alturas para asegurar no sólo la estabilidad bitensional sino también la facilidad de drenaje (Fig. 16).
De nuevo podemos imaginar la cantidad de soluciones posibles, para un mismo programa de necesidades, variando simplemente la forma y altura de los apoyos y combinando apoyos interiores con perimetrales. Aparecen, además, ahora las posibilidades de combinación de apoyos lineales con puntuales, tanto interiores como exteriores, con lo que el número de formas resulta prácticamente ilimitado.

\subsection{Tecnología de diseño}

Apuntadas, de un lado, las repuestas funcionales de la arquitectura textil y vistas, de otro, sus amplias y justificadas posibilidades formales, debemos entrar ya en el estudio de su tecnologia; tecnología que tiene su base en la industria textil, por una parte, en su funcionalidad arquitectónica, por otra, y en su respuesta estructural, como colofón. Se trata, en definitiva, de disponer de los conocimientos técnicos necesarios, como herramienta de diseño, para perder el lógico miedo que toda novedad supone en un sector (especialmente el de la edificación) y tener la libertad que da el conocimiento para acometer los nuevos diseños sin miedo de la ignorancia.

Para ello necesitamos analizar, por lo menos, los siguientes aspectos:

- La tela como material y sus caracteristicas fisicoquimicas que afectarán a su función como cerramiento.

- La confección de la tela en el taller, con los problemas de despiece y uniones.

- Los anclajes de la tela, tanto a los puntos elevados como a los inferiores, analizando con detenimiento los problemas de borde y unión entre superficies distintas.

\subsubsection{La tela como material de construcción}

La tela está constituida básicamente por un tejido o entramado de fibras y una protección que, además, la impermeabiliza.

El tejido, aunque puede ser de muchos tipos, tiene un entramado normalmente octogonal de trama y urdimbre con una separación entre fibras que varía según las exigencias resistentes y de transparencia. Las fibras usadas pueden ser orgánicas, minerales, sintéticas o metálicas, aunque dominan, por sus características mecánicas, las sintéticas y, más concretamente, las de poliester y las de poliamidas. Las orgánicas (lana, algodón, cáñamo, etc.) suelen presentar problemas de durabilidad, y las minerales (fibra de vidrio) de falta de elasticidad, mientras que las metálicas tienen problemas de durabilidad (oxidación) y precio.

La protección puede ser, asimismo, muy variada desde los más sencillos y opacos como la goma y el bitumen, hasta los más transparentes, como el poliester, el PVC y el polietileno (estos dos últimos los más usuales) lle- 
gando en la actualidad al politetrafluoretileno de excelentes características. En cualquier caso, es importante el proceso de aplicación de estas películas, por su contribución a las resistencias mecánicas de la tela, como veremos, y son fundamentales sus caracteristicas de protección, tanto a los rayos ultravioletas exteriores como al posible fuego interior.

Los revestimientos de PVC suelen tener un espesor de $0,2 \mathrm{~mm}$ sobre el punto de cruce de los hilos y puede pigmentarse para reducir la transparencia con polvo de carbón o de aluminio, o, simplemente, mejorando con adición de absorbentes cuando se quiere alcanzar una mayor transparencia.

Los revestimientos de goma (engomados) suelen conferir, por el contrario, una mayor resistencia a la tela, aunque pierden transparencia.

En definitiva resulta una membrana de caracteristicas mecánicas anisotrópicas, debido al entramado, que le confieren mayor resistencia en sus direcciones, aunque la capa de protección puede contribuir a que el material se aproxime a la isotropia al repartir los esfuerzos entre las dos familias de tejidos, según sus propias características. De hecho, en muchas ocasiones, cuando las tensiones a las que va a estar sometida la tela no son excesivas, se calcula como si el material fuese isótropo, lo que facilita, como veremos, su confección. De hecho en el proceso textil se alargan más los hilos de la urdimbre que los de la trama, pudiendo llegar a quedar incluso planos, lo que hace que ésta tenga una mayor elasticidad en servicio y, por tanto, una mayor capacidad de deformación y absorción de tensiones.

\subsubsection{Caracteristicas mecánicas}

Las características mecánicas que más nos interesan son dos: la resistencia a la tracción y la resistencia a la propagación del rasgado.

\section{Resistencia a tracción}

Como quiera que para la estabilidad general la tela debe estar sometida permanentemente a una bitensión de tracción, ésta será la característica más importante que deberemos tener en cuenta. De ella, nos interesará, sobre todo, la máxima tensión de tracción que pueda soportar. Para ello, lo más corriente en este tipo de materiales preparados para resistir tracciones es medir el alargamiento por tracción; concretamente se mide el alargamiento al cual se rompe un hilo que cuelga verticalmente, por su propio peso, con lo cual el tamaño y la sección del mismo no son importantes, sino sólo su peso especifico y su resistencia a tracción. Comprenderemos que en el caso textil esto es lo más adecuado ya que la sección de un hilo es dificil de medir. En cualquier caso, el alargamiento por tracción es especifico para cada material y se expresa en términos de resistencia a la rotura y peso especifico

según la fórmula $\mathrm{R}=\frac{\sigma}{\rho}$, donde:
$\mathrm{R}=$ alargamiento de rotura en $\mathrm{km}$,

$\sigma=$ tensión de rotura en $\mathrm{kg} / \mathrm{mm}^{2}$,

$\rho=$ peso especifico en $\mathrm{g} / \mathrm{cm}^{3}$.

De ahi se deduce que el alargamiento de una fibra es directamente proporcional a su capacidad de tensión e inversamente proporcional a su peso especifico, por lo que cobran importancia las fibras sintéticas, para estas soluciones textiles, frente a las metálicas.

Pero la resistencia y el alargamiento de uno de los hilos no es característica suficiente. A nosotros nos interesa el comportamiento de la tela en su conjunto. Ello, sin embargo, no es sencillo, por lo que la normativa técnica, en aquellos paises donde existe (en Alemania la DIN 53354), a la resistencia a tracción de las telas en $\mathrm{kp} / 5 \mathrm{~cm}$. Para ello se ensayan probetas de tela de $50 \mathrm{~mm}$ de ancho y $300 \mathrm{~mm}$ de longitud libre de fijación. La resistencia final de tracción depende del hilo, del número de ellos y, en cierta medida, del material de protección. Para tener una idea, las telas del mercado actual varian desde resistencias de $200 \mathrm{kp} / 5 \mathrm{~cm}$, para espesores de $0,52 \mathrm{~mm}$ y pesos de $540 \mathrm{~g} / \mathrm{m}^{2}$, hasta los $2.000 \mathrm{kp} / 5 \mathrm{~cm}$, para espesores de $3,5 \mathrm{~mm}$ y pesos de $3.200 \mathrm{~g} / \mathrm{m}^{2}$, pudiendo considerarse una tela intermedia la que tuviera una resistencia de $400 \mathrm{kp} / 5 \mathrm{~cm}$, un espesor de $0,9 \mathrm{~mm}$ y un peso de $1.000 \mathrm{~g} / \mathrm{m}^{2}$.

\section{Resistencia a la propagación del rasgado}

El colapso en este tipo de estructuras puede aparecer no sólo por rotura de la tela al sobrepasar la tensión de tracción máxima, sino también por rasgado a partir de una primera incisión debida a cualquier causa. De ahi que cobre importancia esta segunda característica mecánica. En ella participa, de un modo directo, la protección superficial del tejido y, más concretamente, la adherencia entre ambos, ya que ello contribuirá definitivamente a resistir el esfuerzo de rasgadura; de ahi que, en ocasiones, se sustituya esta característica mecánica por la «resistencia al pelado», es decir, el arraṇcamiento de la capa protectora. La resistencia al rasgado (a su propagación) se mide directamente en $\mathrm{kp}$ y suele variar entre los $20 \mathrm{kp}$ y los $300 \mathrm{kp}$, independientemente de su resistencia a la tracción, aunque con carácter general se puede considerar que está entre un 10 y un $15 \%$ de la tracción. En cualquier caso, depende no sólo de las capas de protección, sino, y sobre todo, de la forma y tipo de tejido, apareciendo la menor resistencia cuando cada hilo se rasga independientemente y éstos permanecen separados unos de otros.

\section{Influencia de la humedad y la temperatura}

Ambas resistencias, tanto la de la rotura como la de rasgado, varian según las condiciones ambientes de humedad y temperatura y, asimismo, de la duración del periodo de carga.

Por lo general, cuando aumenta la temperatura disminuye la resistencia a tracción, incrementándose, sin embar- 
go, la capacidad de deformación. Lo contrario ocurre cuando la temperatura baja. No obstante, la mayoria de los autores admiten que las características mecánicas no sufren una alteración sensible entre temperaturas de -25 $\mathrm{y}+70^{\circ} \mathrm{C}$. También influyen en este aspecto los revestimientos, de tal manera que, por ejemplo, un vulcanizado permite un mejor comportamiento ante altas temperaturas $\left(+180^{\circ} \mathrm{C}\right)$ que un $\mathrm{PVC}$.

En cuanto a la humedad, afecta a la estabilidad dimensional de los hilos del tejido, en función de su recubrimiento y del propio hilo. Concretamente, está comprobado que la fibra de poliester es más estable ante este agente que la de poliamida, por lo que su uso es más general. Esta muestra una tendencia al estiramiento.

\subsubsection{Características fisicas}

$\mathrm{Al}$ actuar la tela no sólo como estructura, sino también como cerramiento, cobran importancia otras caracteristicas fisicas que cabe considerar; concretamente, su durabilidad, sus coeficientes de aislamiento térmico y acústico y su coeficiente de transparencia luminosa.

\section{Durabilidad}

El tiempo es uno de los "agentes» más agresivos para cualquier material de construcción, sobre todo si se usa en cerramientos exteriores; tiempo que debe considerarse siempre en relación con los agentes climáticos, temperatura, humedad y radiación solar, fundamentalmente. Ya hemos visto cómo la humedad y la temperatura afectan a las caracteristicas mecánicas de la tela y cómo las radiaciones ultravioletas pueden perjudicar a las de la fibra, concretamente. El conjunto de estos factores (material de la fibra, tipo de tejido, tipo de protección, etc.) nos dará la durabilidad de la tela. La mayoria de los fabricantes garantizan una vida útil de la tela de 20 años, siempre que esté sometida a las condiciones físicas previstas, aunque podemos considerar que la resistencia a tracción tiende a disminuir aproximadamente un $20 \%$ en los 10 primeros años para después mantenerse casi constante. La tabla 1 muestra las curvas de disminución de la resistencia de una tela con el tiempo, según su fabricante.

Pero hay otros agentes que pueden condicionar la durabilidad de las telas y que dependen de su uso. El más importante, y a la vez más analizado, es el fuego. Como quiera que es un agente muy estudiado y condicionado por la normativa en la mayoria de paises, los fabricantes se han preocupado de su protección. En Alemania Federal se suele exigir, cuando se trata de espacios cerrados, que cumplan las normas DIN 4102, de combustión de cámara, y DIN 53906 y 53907, de resistencia al fuego de textiles con probetas sostenidas horizontal y verticalmente, resultando positivas para la mayoria de las telas usadas para grandes cubiertas.

En EE.UU suelen pasar satisfactoriamente los ensayos indicados en las normas ASTM-84, 108 y 136, sobre
Tabla 1.-Evolución de la resistencia a tracción con el tiempo

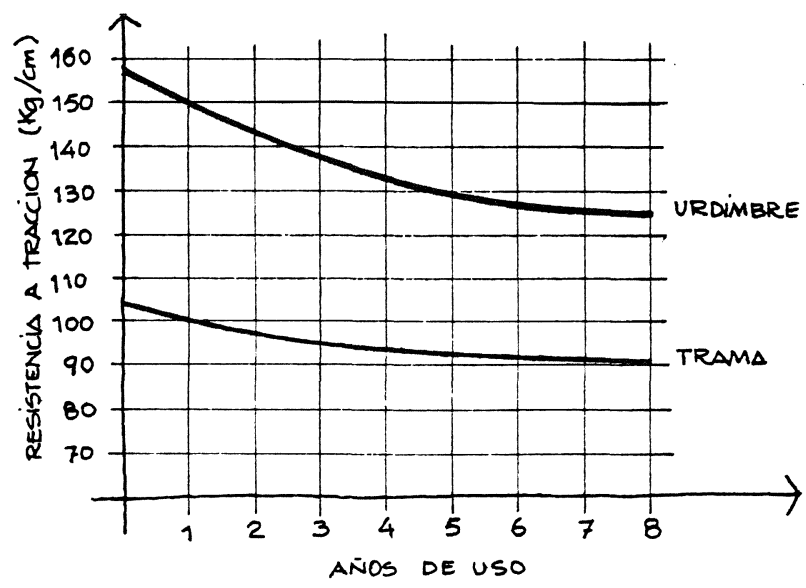

combustibilidad e inflamabilidad. En definitiva, se puede decir que estos tipos de telas están o deben estar compuestas de un tejido incombustible, con una protección resistente a la llama que, en cualquier caso, debe ser capaz de resistir al fuego el tiempo que determine la normativa al caso según el uso que se le quiera dar. En este sentido deberemos distinguir, sobre todo, entre telas como cerramiento y telas como toldos. En las primeras las exigencias serán, obviamente, mayores.

En nuestro pais, y de acuerdo con la norma NBE-CPI, de condiciones de protección contra incendios, deberemos obtener, en primer lugar, una clasificación del material por su reacción contra el fuego según UNE 23-72780. A continuación los anejos del A1 al A10 de la norma, nos darán la resistencia al fuego del cerramiento exigida según el uso del edificio.

\section{Aislamiento térmico y acústico}

No cabe duda que la tela como material de construcción de un cerramiento no puede presentar grandes coeficientes de aislamiento debido a su poco peso y espesor, por lo que las condiciones térmicas y acústicas del espacio encerrado habrá que obtenerlas por vía del diseño. Ya hemos mencionado los efectos invernadero y sombrilla para el ambiente térmico y algo similar habrá que buscar para el acústico. No obstante conviene mencionar, aunque sea esquemáticamente, las características físicas más destacadas en estos sentidos.

El coeficiente de transmisión térmica $\mathrm{K}$ de estas telas puede variar entre 6,2 y $4,1 \mathrm{kcal} / \mathrm{h} \mathrm{m}^{2}{ }^{\circ} \mathrm{C}$ para una tela simple. Sin embargo, si colocamos dos telas paralelas, podemos aprovechar el efecto invernadero que se forma entre ellas (Fig. 17) y disminuir considerablemente el coeficiente de transmisión a valores del orden de $2 \mathrm{kcal} /$ $\mathrm{h} \mathrm{m}{ }^{2}{ }^{\circ} \mathrm{C}$. Si seguimos añadiendo hojas de tela ( 3 hojas es relativamente fácil) podremos disminuir todavía más el coeficiente de transmisión térmica. Unicamente habrá que considerar la relación precio-aislamiento. 


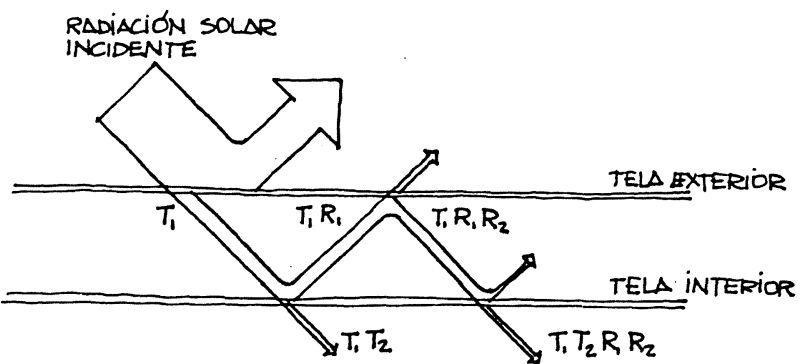

$$
\begin{aligned}
& T \cdot \text { TRASMISION } \\
& R-\text { REFLEXIóN }
\end{aligned} \quad T_{c}=100 \times \frac{T_{1} T_{2}}{1-R_{1} R_{2}}
$$

Fig. 17.-Calentamiento por doble tela.

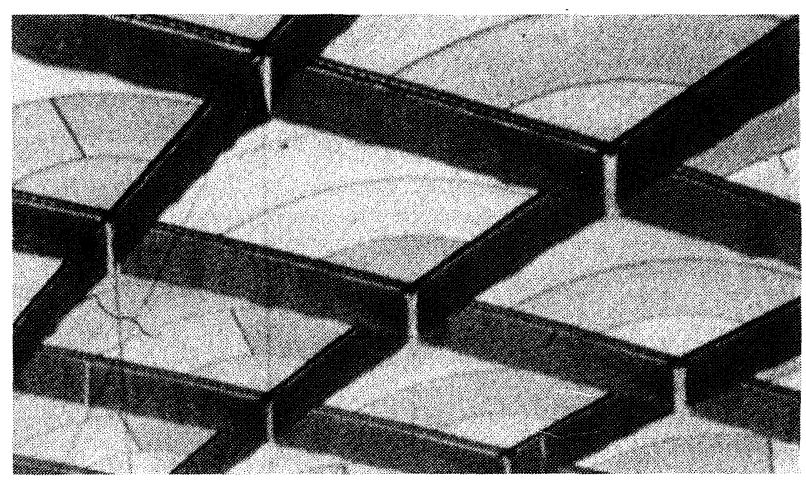

Fig. 18.-Bandas acústicas

En cuanto al acústico, en este tipo de cubiertas el aspecto más importante no es el aislamiento del ruido exterior, para el que las telas suponen una barrera muy débil, sino, sobre todo, el acondicionamiento interior, es decir, la disminución de las reflexiones interiores. Como quiera que la superficie resultante es muy lisa, la absorción de reflexiones deberá basarse en la adición de algún tipo de rugosidad o de material absorbente. Para la rugosidad es bastante corriente el añadir unas bandas a la superficie de la tela, que tienen la misión de "romper» las reflexiones (Fig. 18). Es una solución empleada, sobre todo, en grandes cubiertas soportadas por aire, donde la curvatura cóncava hacia el interior facilita la concentración de las reflexiones en el ambiente que cubre, aumentando, por tanto, el nivel de sonido interior.

En cuando a materiales más absorbentes, la mayoria de los fabricantes producen unos tipos de tejidos especiales, con un alto poder de absorción por su estructura y porosidad, para su uso en el ambiente interior. Estos tejidos pueden colocarse, bien en bandas perpendiculares, como queda mencionado en el párrafo anterior, bien en una hoja de tela adosada a la estructura, solución que puede ser empleada fácilmente en las cubiertas colgadas y que puede alcanzar un coeficiente de reducción de sonido del 0,65 en cubiertas integrales.

\section{Transparencia}

Es, quizá, la característica fisica de las telas que resulta más aprovechable para lograr un ambiente interior atrac- tivo, además de la propia cubierta como protección de la lluvia y del sol. En efecto, la transparencia implicita en la tela le confiere un carácter de foco de luz difusa, suficientemente alta como para lograr unos niveles de luminancia interior muy agradables y adecuados para todo tipo de actividades, y suficientemente matizada con respecto al soleamiento directo, como para no necesitar ningún tipo de protección adicional. Pero además, la gran ventaja de estas telas es que en su fabricación se puede incidir en su coeficiente de transparencia, consiguiéndolo mayor o menor según las necesidades de luminancia interior.

Con carácter general la figura 19 representa el funcionamiento de una tela frente a la radiación solar, en la que vemos que, como término medio, de la radiación total incidente (suma de la directa del sol más la difusa de la atmósfera) alrededor de un $70 \%$ es reflejada directamente mientras que un $15 \%$ pasa también directamente al interior, y otro $15 \%$ es absorbida, en un principio, por la tela, que, en consecuencia, actúa como nuevo foco difusor de energia, reflejando la mitad hacia el exterior e introduciendo la otra mitad hacia el ambiente interior en forma de energia calorifica. En definitiva, resulta un coeficiente de transparencia luminosa muy próximo al $15 \%$ con carácter general, lo que indica que si consideramos, por ejemplo, un cielo tipo CIE en el exterior de 5.000 lux, obtendriamos una luminancia interior, en principio, de 750 lux, que es muy adecuada, incluso para actividades de precisión. Pero, además, el foco de iluminación que tendríamos seria toda la superficie de la tela, lo que resulta sumamente agradable, pues supone un tipo de fuente luminosa muy homogénea, sin contrastes excesivos ni deslumbramientos, y con una gran uniformidad de iluminación, al llegar la luz desde todas las direcciones.

Las telas actuales en el mercado presentan una gama de transparencias que suele variar entre el $5 \%$ (para telas muy opacas - poca necesidad de iluminación) y el $30 \%$ (telas muy transparentes - mayor necesidad de iluminación) lo que nos permite adaptarnos a diversas situaciones exteriores así como a diferentes necesidades ambien-

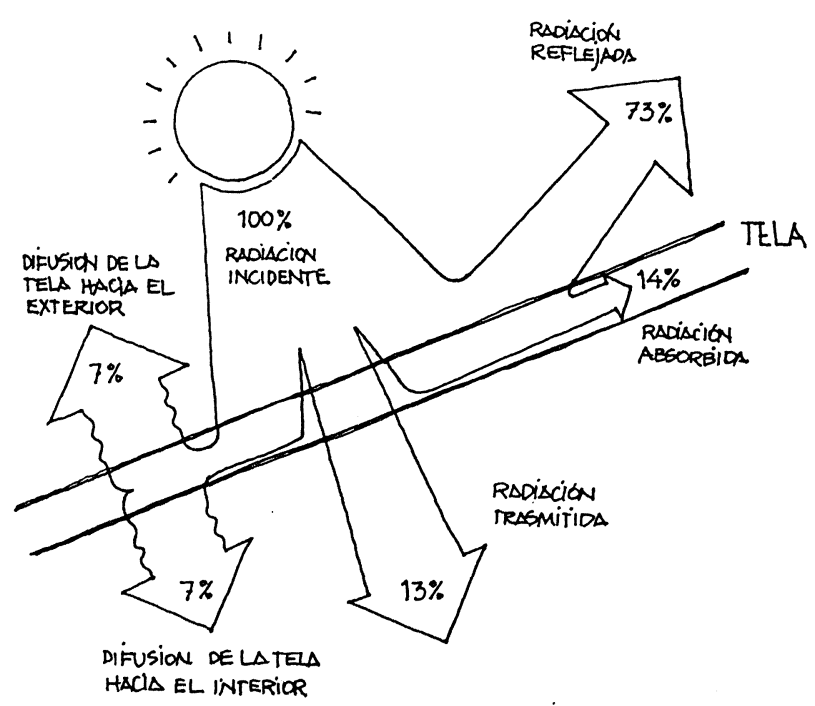

Fig. 19.-Distribución de la radiación solar en una tela del mercado. 
tales interiores. Cuando sea necesaria oscuridad total, se pueden utilizar telas opacas, con un coeficiente de transparencia de $0 \%$.

Este funcionamiento de la tela frente a la radiación solar incidente, nos da idea de su posible aprovechamiento para el ambiente térmico interior, tanto para conseguir el efecto invernadero, como para el efecto sombrilla que mencionábamos anteriormente, jugando con las exigencias del ambiente interior, las caracteristicas reflectantes de la tela y el diseño de la cubierta. Sobre ello incidiremos más adelante.

\subsubsection{La confección}

La tela, como material industrial, se suministra en bobinas de anchos relativamente reducidos que varian entre 1,2 y 2,0 m como término medio, aunque una firma comercial de Estados Unidos es capaz de suministrar bobinas de hasta $4,9 \mathrm{~m}$ de ancho.

No obstante, y en cualquier caso, estas son dimensiones que no suelen ser suficientes para las superficies que queremos cubrir, por lo que es necesario siempre ir a la unión de una serie de piezas de tela para conseguir la superficie total necesaria. Por otro lado, esta superficie necesita un remate de borde (al igual que las telas para vestir) que nos asegure su integridad y que nos permita su unión a la estructura que la va a sustentar o anclar. Veamos los aspectos más importantes de estos extremos:

\subsubsection{Patrones de corte}

Para obtener la superficie total que necesitamos mediante la unión de trozos de tela de tamaño reducido, el primer paso será fijar la forma y dimensión de estos trozos, al igual que hace cualquier sastre para la confección de un traje de vestir. Precisamente por esta analogia, a esos trozos de tela con forma definida les podemos llamar «patrones». Su diseño será fundamental para obtener, con el mínimo de tela imprescindible, la forma y la curvatura total buscadas sin que aparezcan tensiones diferenciales en las uniones de los patrones, bien por falta de tela en alguno de ellos (aparecen tensiones excesivas) o por exceso de material (aparecen arrugas). Esta es una operación relativamente complicada y requiere especialistas para su desarrollo. Por ello vale la pena que nos detengamos algo en su análisis.

Si nosotros queremos obtener una superficie plana y cuadrada, no hay duda que la manera más fácil será unir en paralelo tiras de tela del ancho de la bobina que nos suministre la industria, para conseguir un máximo aprovechamiento de la tela dentro de esas caracteristicas geométricas. Si la superficie en lugar de ser rectangular es poligonal de cualquier tipo, bastará partir del lado mayor como referencia y tendremos trozos de tela de forma trapezoidal en el que únicamente nos preocupará el máximo aprovechamiento de la tela (Fig. 20). Sin embargo, sabemos que una de las condiciones fundamentales para las estructuras de tela es la curvatura de la superficie resultante, por lo que la confección se complica algo.

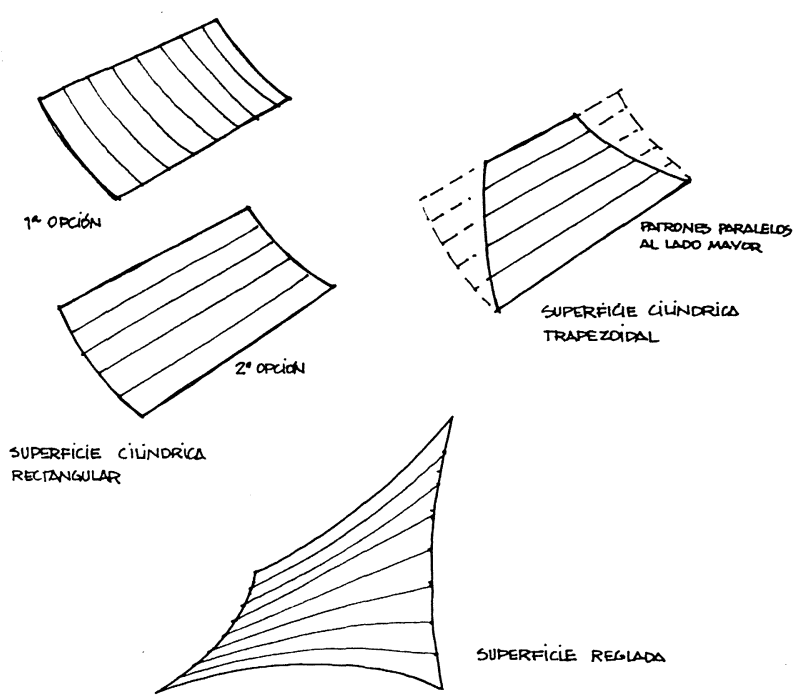

Fig. 20.-Despieces de patrones tipo.

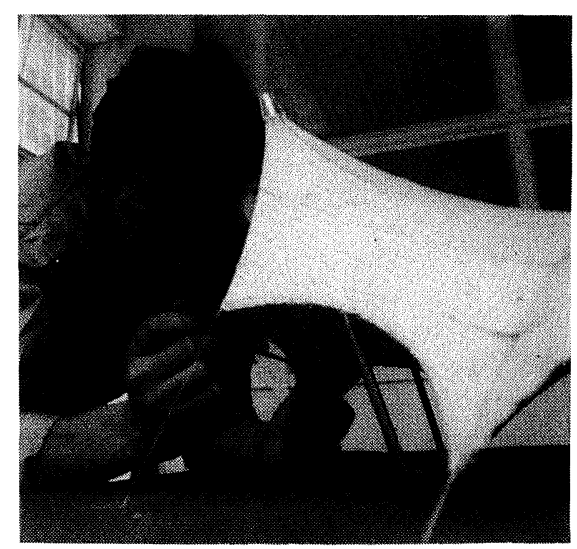

Fig. 21.-Despiece de patrones sobre maqueta.

Si la curvatura fuera simple (un cilindro, por ejemplo) su solución seguiria siendo fácil ya que un cilindro resulta una superficie "desenrollable» y, por tanto, convertible en otra superficie plana, y entonces nos encontramos en el caso anterior. Pero no sólo hemos exigido curvatura, sino doble curvatura en cada punto, por lo que el proceso de confección se complica algo más.

Si la doble curvatura pudiera ser sinclástica, como en el caso de las cubiertas hichadas por aire que veremos más adelante, podriamos tratar de asimilar cada sector de la cubierta a un casquete esférico, que, por ser figura geométrica primaria y muy estudiada, tiene la descomposición de su superficie resuelta de varias formas, todas ellas posibles de traducción en trozos de tela (por meridianos, por paralelos, icosaédrica, etc.). Pero para las cubiertas colgadas y en tensión, hemos exigido una curvatura anticlástica en cada uno de los puntos de su superficie, por lo que la complicación es definitiva. No obstante la solución es posible y la prueba son todas las cubiertas existentes. Para ello, lo más fácil y práctico es realizar maquetas a escala precisa, con la forma que queremos obtener, mediante el uso de telas elásticas que adquieran las curvaturas necesarias, y sobre ellas dibujar exactamente los patrones que, una vez unidos, nos reproducirán exactamente la misma superficie (Fig. 21). 
Otra solución, posible en algunos casos, es aprovechar el hecho de que algunas superficies de doble curvatura son superficies regladas, lo que permite confeccionarlas a base de trozos de tela paralelos. Es el caso del paraboloide hiperbólico o "silla de montar», muy útil como superficie para cubiertas colgadas de planta rectangular con apoyos perimetrales.

En cualquier caso, y con carácter general, podemos establecer los siguientes puntos como objetivos a seguir en el diseño de los patrones de una cubierta («corte y confección»:

- Máximo aprovechamiento de las bobinas de suministro, tratando de descomponer en patrones rectangulares el mayor porcentaje de la superficie total.

- Atención a las tensiones de la cubierta a los efectos de considerar la dirección de la tensión máxima con respecto de la del tejido de la tela, sobre todo si ésta no es isótropa.

- Atención a las inflexiones bruscas de la cubierta, procurando que coincidan con uniones de patrones que sean susceptibles de refuerzos adicionales.

- Procurar que no aparezcan patrones excesivamente puntiagudos que dificulten la confección.

\subsubsection{Uniones}

Una vez obtenidos los patrones, hay que unirlos entre si para obtener la superficie total deseada. Estas uniones tienen que ser tales que no se distingan del resto de la tela en su función. Es decir, no son uniones constructivamente funcionales o necesarias, sino que, una vez realizadas, tienen que desaparecer como tales y actuar como parte de todo el conjunto. En definitiva, a las uniones les tenemos que exigir, por lo menos, las mismas caracteristicas mecánicas y físicas que al resto de la tela. No obstante, sabemos que no vamos a poder evitar que, al ser uniones
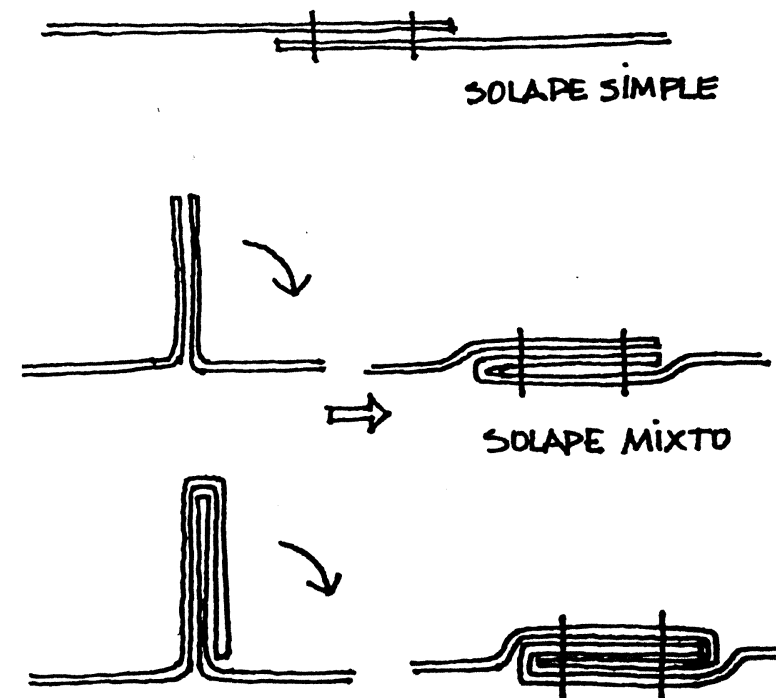

Fig. 22.-Juntas cosidas.

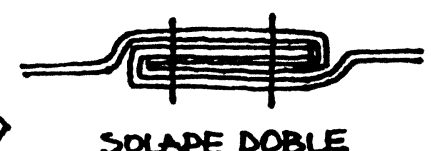

SOLAPE DOBLE lineales, se concentren a lo largo de su directriz algunas de las tensiones de las que actúen sobre las telas adyacentes, por lo que necesitaremos reforzarlas mecánicamente según esa dirección. Debemos conseguir, por tanto, una correcta actuación ante las siguientes acciones:

- Mecánicas:

- Tensiones según su directriz.

- Tensiones perpendiculares.

- Elasticidad igual a las telas adyacentes.

- Físicas:

- Estanquidad.

- Impermeabilidad.

- Resistencia al fuego.

- Quımicas:

- Resistencia a rayos ultravioletas de los materiales aportados en la junta.

Teniendo en cuenta todos esos extremos, veamos los distintos tipos de juntas más usuales.

\section{Juntas cosidas}

Son las más tradicionales y consisten, básicamente, en la unión de los bordes de las dos telas contiguas mediante dos o más costuras paralelas.

Aparecen varios tipos según el sistema de solape que se utilice (Fig. 22). Asi tenemos juntas con solape simple, con solape mixto (doble en una de las telas y sencillo en la otra) y con solape doble en cada una de las telas. $\mathrm{Na}$ turalmente, cuanto más compleja, más segura e impermeable, pero exige mayor cantidad de tela perdida en los bordes.

En cualquiera de los casos existe una aportación de un nuevo material en la ejecución de la junta - el hilo de la
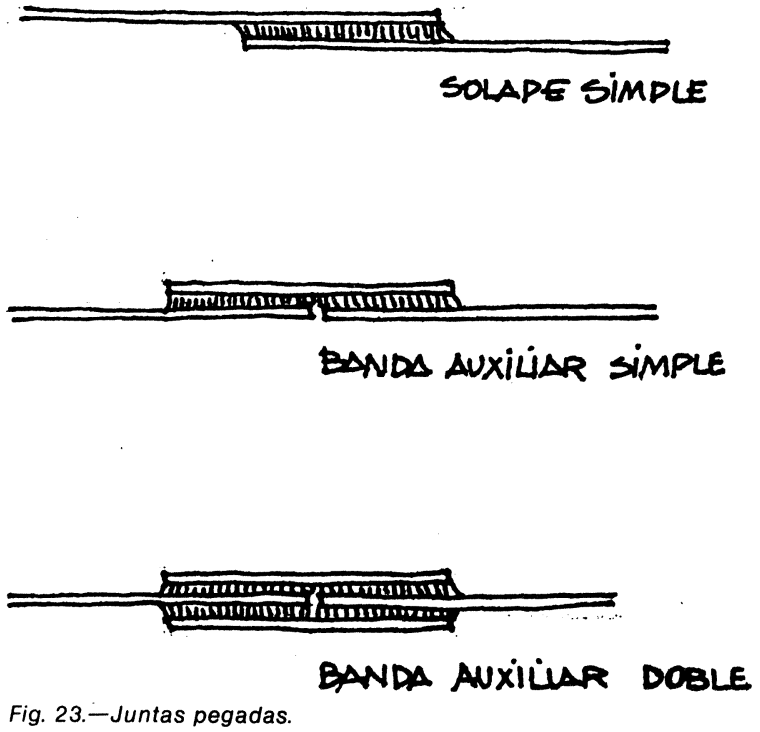
costura- y éste, junto con la sucesión de perforaciones, son los factores que pueden introducir problemas en el funcionamiento de la junta. Por una parte, tenemos el peligro del ataque de los rayos ultravioletas ya que el hilo está, en principio, desprotegido; por ello resulta importante aplicar un barniz de composición similar al que constituye la protección de la misma tela. Por otra, aparece la posibilidad de rasgados, bien de la tela por los agujeros de paso del hilo, bien por rotura del propio hilo si no tiene la resistencia suficiente, debidos, en cualquier caso, a la concentración de tensiones en la junta mencionada más arriba.

\section{Juntas pegadas}

Son juntas de fácil y rápida ejecución y, por tanto, muy indicadas para reparaciones de telas utilizadas, incluso realizadas «in situ».

Pueden considerarse también varios tipos según el tipo de solape (Fig. 23). Así tenemos, de nuevo, las de solape simple, con el pegamento entre medias, las de banda auxiliar simple y las de banda auxiliar doble, que es la de mayor resistencia y estanquidad. En estas dos últimas, además, puede conseguirse un pequeño ahorro de tela, ya que los bordes de los patrones adyacentes quedan a tope, siempre que se consiga hacer las bandas auxiliares mediante retales.

Como material de pegamento es recomendable utilizar el mismo que se ha empleado para proteger el tejido de la tela, con lo que la adherencia de la unión es muy resistente, incluso superior a la que existe entre la protección y el tejido. Existe, no obstante, y según el pegamento que se utilice, el peligro de que las altas temperaturas le afecten y, por difusión plástica, pierda resistencia, apareciendo el rasgado por la propia junta.

\section{Juntas soldadas}

Son las juntas más modernas $\mathrm{y}$, a la vez, más efectivas. Consisten en aprovechar la capacidad de reblandecimiento y fusión de los materiales termoplásticos que constituyen la protección de las telas. Para su ejecución bastará calentar por algún procedimiento los bordes a unir, solaparlos y someterlos a presión hasta que se solidaricen.

Los procedimientos de calentamiento son variados, desde el contacto con herramientas calientes, hasta las altas frecuencias.

La presión se suele conseguir mediante unos rodillos que avanzan sobre la unión a velocidades entre 3 y $5 \mathrm{~m} / \mathrm{min}$., lo que permite una ejecución muy rápida. En cualquier caso, es fundamental que la capa de protección de material termoplástico esté repartida en partes iguales a ambos lados de la tela y que el calentamiento no afecte al tejido.

Los tipos de juntas según el sistema de solape son los mismos que veíamos para juntas pegadas.

\section{Juntas grapadas}

Es un tipo de unión menos estanco, impermeable y resistente que cualquiera de los anteriores, por lo que su uso debe limitarse a casos con niveles de exigencia menores.

El grapado puede ser de varios tipos según la herramienta y grapa que se use y según el tipo de solape (Fig. 24). Asi tenemos el grapado simple, el grapado con doble solape, grapados en un solo lado que dejan el solape perpendicular a la tela y el grapado con solape paralelo a la superficie textil.

También son variados los tipos de grapas, desde las similares a las que se usan para los papeles, con dos perforaciones o con una sola, hasta los remaches automáticos, pasando por los tipos de atornillados. (Estos dos últimos pueden combinarse con una pletina metálica longitudinal que refuerza la unión en su conjunto).

\section{Juntas practicables}

Los tipos de uniones vistas hasta aquí pueden considerarse como uniones permanentes por su sistema de ejecución. Sin embargo, hay ocasiones en que, para la utilización e incluso montaje, puede ser conveniente dividir la superficie total en varios tramos que se tienen que poder unir y separar con relativa facilidad. Aparece entonces la necesidad de las uniones practicables.

Las exigencias sobre ellas pueden ser muy variables según su localización $\mathrm{y}$, por tanto, esfuerzo mecánico que vayan a soportar o agentes físicos que vayan a sufrir. Por ello aparecen varios tipos a considerar (Fig. 25).

\section{Cremalleras}

Son las más sencillas de manejo y las que presentan menor posibilidad de arrugas, así como mayor estanquidad al agua, aunque sea conveniente colocar encima una banda auxiliar de protección. Exigen, sin embargo, un mantenimiento cuidado para evitar la apertura de alguno de los eslabones, lo que produciría el rasgado de la unión.

\section{Acordonados}

Son también sencillas de manejo aunque más lentas de ejecutar (hacer y deshacer). Consisten en unir los bordes de la junta mediante unos lazos colocados en uno de ellos, que pasan por unos ollaos ejecutados en el otro y que se enganchan entre sí. Presentan poca seguridad y puede ser conveniente también una banda auxiliar de protección. Por su sistema de ejecución y por la cantidad de puntos de rozamiento no presenta una gran durabilidad. 

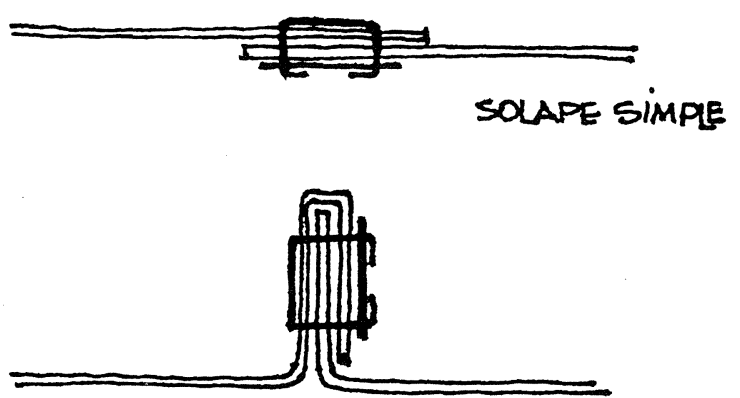

SOLAPE FERPENDIC.

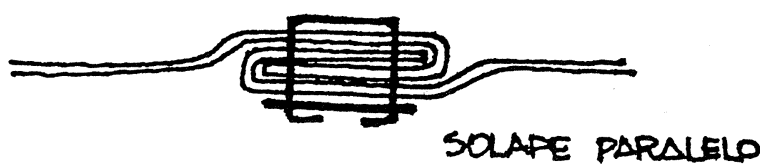

Fig. 24.-Juntas grapadas.

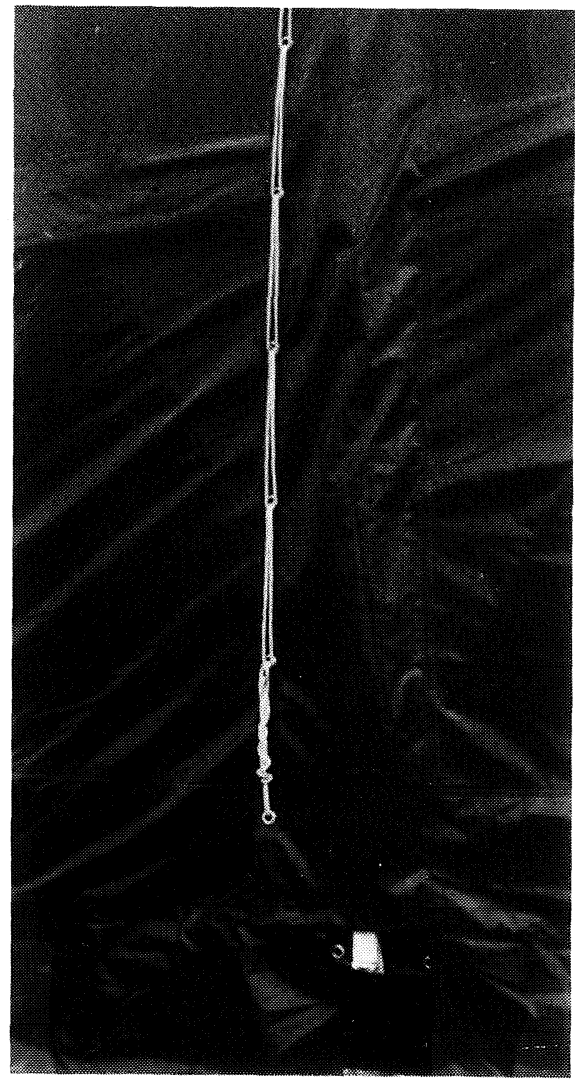

Junta practicable acordonada.
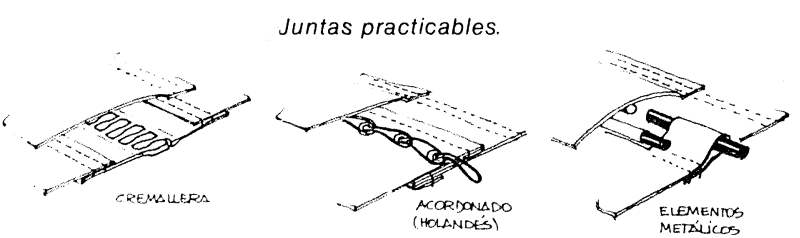

Fig. 25.

\section{Elementos metálicos}

Existen multitud de tipos y se basan en el uso de diferentes elementos metálicos que se conectan entre sí procurando siempre el suficiente solape de los bordes de la tela. Son uniones por puntos, como la anterior, por lo que sus resistencias, tanto mecánica como física, no son muy elevadas.

\subsubsection{Bordes}

Uno de los puntos débiles de cualquier membrana es su borde, puesto que en él tienden a concentrarse las tensiones que la membrana está soportando en todas las direcciones en cualquier punto de su superficie. En efecto, al aparecer una interrupción de la membrana, las tensiones de tracción cuya dirección se ve interrumpida, se transforman en nuevas tensiones que tienden a acumularse en la dirección del corte para contrarrestar las que quedan en el lado de la membrana que permanece, suponiendo que este borde quede suelto. Si se fijase de un modo continuo, las tensiones se transmiritirian al sistema de fijación (Fig. 26). Por ello, resulta importante prestar atención a la ejecución del borde en las telas colgadas que estamos analizando.

Por similitud con las soluciones textiles de la navegación podemos denominar "relinga» a dicho borde que, por todo lo anterior, consistirá en un elemento de refuerzo que sea capaz de absorber las tensiones de tracción longitudinales que se acumulen en el borde entre los puntos de fijación o anclajes. Puede resolverse de varias formas que, en cualquier caso, deberá encajar en cada uno de los binomios siguientes:

- Flexible - rigida.

- Interior - exterior (Fig. 27).

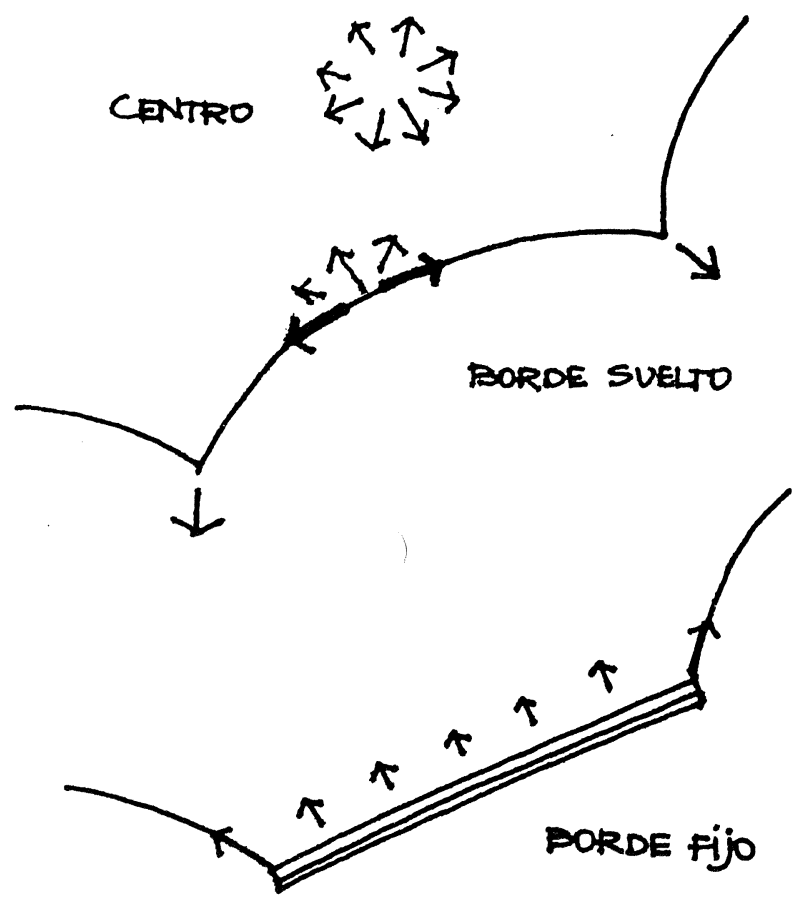

Fig. 26.-Esfuerzo en borde 


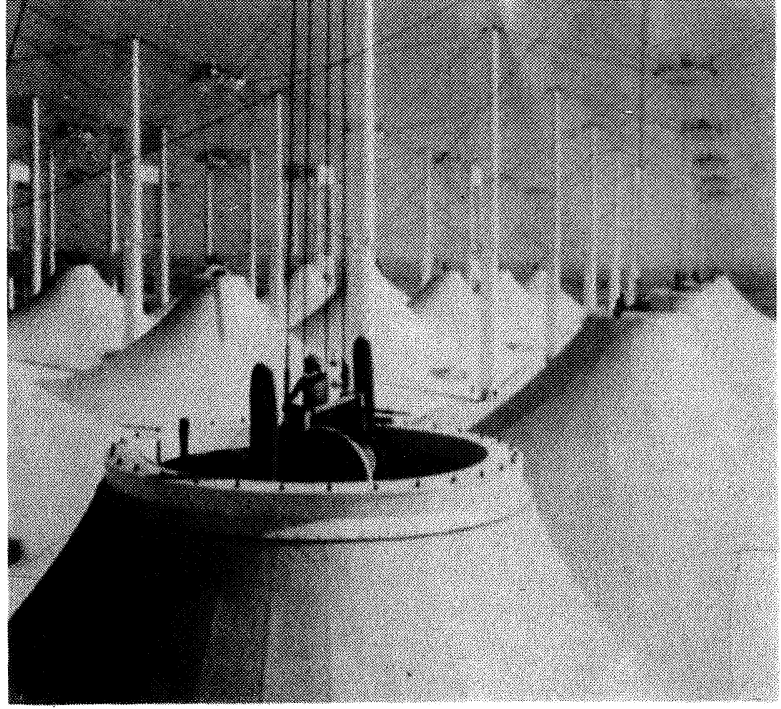

Relinga rigida circular en apoyo interior.
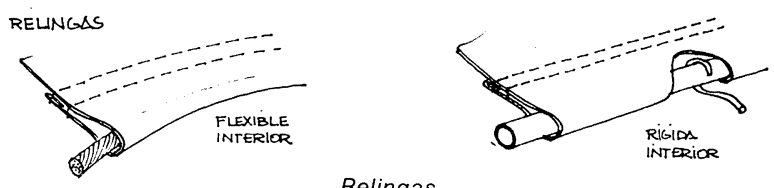

Relingas

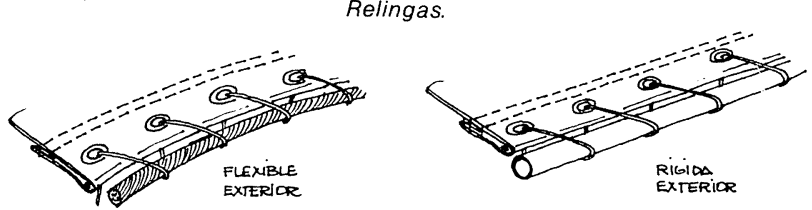

Fig. 27.

La flexible (que podemos considerar como relinga propiamente dicha) se ancla por puntos y entre ellos se deforma según las tensiones de la tela hasta equilibrarlas con la suya propia. Si es interior, suele consistir en un cordón de fibra, similar al utilizado para confeccionar el tejido, que se introduce en un dobladillo practicado en el borde de la tela (los casos en que la tensión prevista sea muy baja, puede llegar a suprimirse el cordón interior y quedar como refuerzo el propio dobladillo). También puede utilizarse un cable metálico para tensiones muy fuertes y limitación de la deformación en su sentido; hay que cuidar, entonces, la acumulación de agua en el interior del dobladillo, lo que podría provocar la oxidación del cable y su rotura. Si es exterior, consiste en un cable que se une al borde de la tela mediante un cordón que pasa por unos ollaos previstos en aquél. En estos casos la tela debe tener algún tipo de refuerzo de borde, aunque sólo sea el simple dobladillo, para que los ollaos no produzcan rasgadura, por lo que el cable exterior constituye una especie de relinga de refuerzo que tiende a absorber la parte más importante de las tensiones. En cualquier caso, es importante cuidar el cordón de atado del cable a la tela, pues su rotura provocaría el despegue de ésta e, incluso, su posible rotura al perder el refuerzo del borde.

La relinga rigida, supone un paso intermedio entre la flexible y la fijación perimetral continua. En efecto, constituye un elemento de borde, fijado por puntos, que está sometido principalmente a flexión, absorbiendo el es- fuerzo de la tela a la que se une. También puede ser interior y exterior. Si interior, se suele resolver con un tubo metálico circular introducido en el dobladillo del borde, que deja unos puntos abiertos para que se pueda producir el anclaje de la relinga. Si exterior, su unión a la tela se realizará por el mismo sistema de cordón y ollaos que veíamos antes y su anclaje puede ser en cualquier punto. En ambos casos la distancia entre anclajes dependerá de la inercia del perfil metálico empleado con objeto de que su deformación no sobrepase los límites permitidos.

Cuando la cubierta textil sufre una inflexión brusca por su diseño, la linea de dicha inflexión recibe la acumulación de tensiones por las mismas razones expuestas anteriormente, por lo que, a los efectos mecánicos, deberá actuar y resolverse como una relinga. La solución puede consistir en un refuerzo longitudinal mediante cordón o cable sujeto a la tela y colocado por un lado u otro de la superficie y preferentemente protegido. Si se coloca en la parte convexa, puede ir simplemente apoyado sobre la tela, incluso sin proteger, aunque convendria, por lo menos, fijarla a fin de que el roce con la tela, por movimiento relativo de ambos, no la dañe. Si lo colocamos en la parte cóncava, habrá que "colgarlo» de la tela, bien mediante banda continua, bien por puntos (Fig. 28).

Como quiera que dicha acumulación de tensiones es siempre peligrosa, se puede eliminar, sustituyendo la arista viva, y por tanto el refuerzo lineal, por una banda de tela continua que convierte la arista en una nueva superficie anticlástica, tensionada en ambas direcciones,

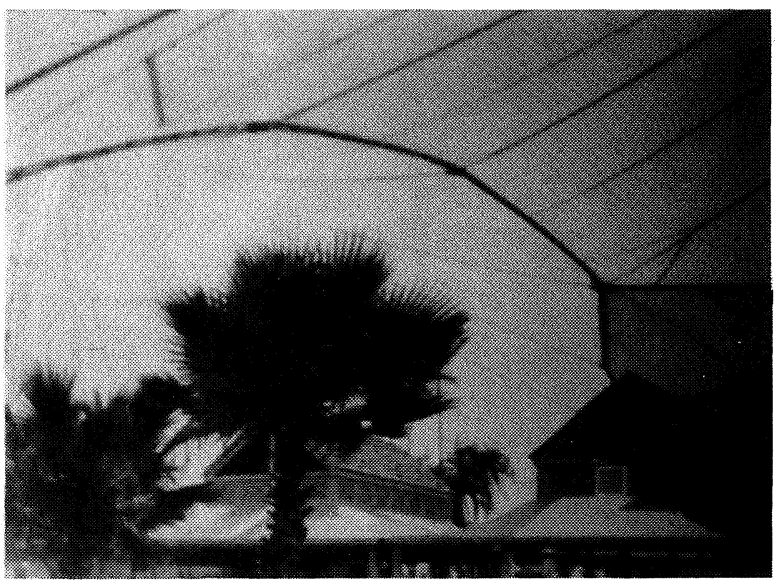

Refuerzo longitudinal en encuentro entre superficies.

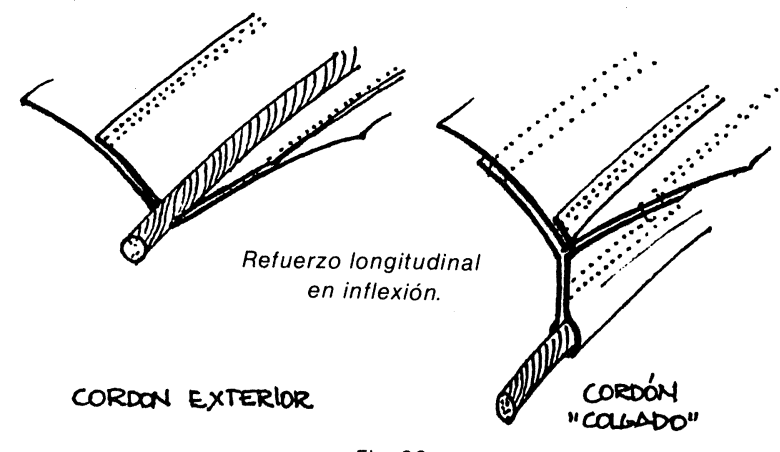

Fig. 28. 


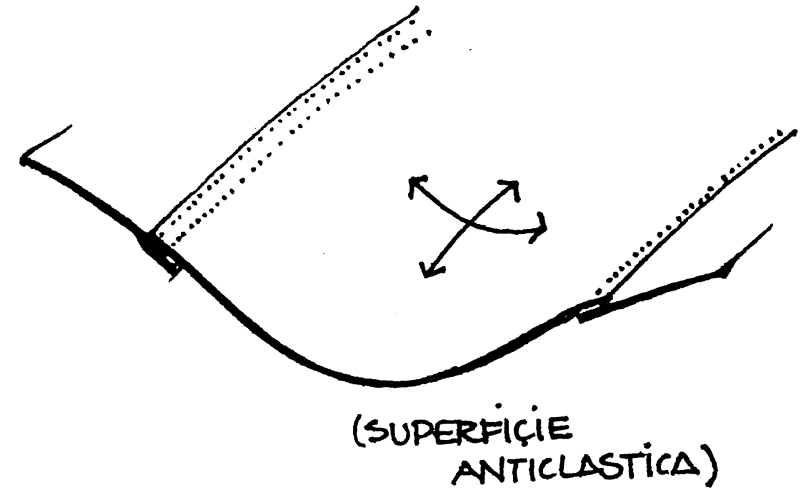

Fig. 29.-Refuerzo con banda.

que trabaja del mismo modo que el resto de la tela. En estos casos, cuanto más ancha sea la banda, menor será la curvatura transversal en cualquier punto y, por tanto, la distribución de tensiones será más uniforme y, por ende, menos peligrośa (Fig. 29).

\subsubsection{Anclajes}

Para conferir estabilidad y poder introducir y mantener las tensiones necesarias, hay que fijar la tela en una serie de puntos. A estos los podemos llamar «anclajes». En ellos, como resulta evidente, se van a concentrar también las tensiones pues van a suponer siempre interrupciones de la tela o cambios de su curvatura. Por ello resulta importante analizarlos y resolverlos correctamente.

Podemos distinguir, en primer lugar, dos tipos claramente diferenciados, interiores y exteriores o perimetrales, que coinciden con las clasificaciones morfológicas que hemos establecido en apartados anteriores.

Podriamos, en principio, distinguir también entre puntuales y lineales para seguir con la analogía anterior. Sin embargo los anclajes lineales son, a su vez, asimilables a las relingas rigidas, por lo que concentraremos nuestra atención en los puntuales, si bien mencionaremos algún tipo especial de anclaje lineal.

En cualquier caso, tanto unos como otros podrán ser positivos o negativos, es decir, suponer un esfuerzo hacia arriba (estar «colgada» la tela) o un esfuerzo hacia abajo (estar «atirantada»).

Los anclajes interiores pueden resolverse, básicamente, de dos maneras, buscando siempre la solución de la concentración de los esfuerzos mecánicos, por una parte, y la de su función básica, por otra.

Uno de los tipos de soluciones consistirá en establecer un apoyo que sea capaz de levantar o bajar la tela sin producir incisiones bruscas que pudieran ser origen de rasgaduras. Para ello, lo más adecuado será recurrir a casquetes esféricos, más o menos grandes, que empujan la tela sin introducirle cambios bruscos de curvatura. Dicho casquete esférico se podrá obtener, bien a base de una superficie esférica propiamente dicha, bien a base de lazos, en forma de rosetas, que mantengan la curvatura (Fig. 30).

En ambos casos el casquete podrá «empujarse» desde la parte cóncava de la tela o "engancharse» desde la parte convexa, lo que nos da idea de la versatilidad de estas soluciones. En cualquier caso, necesitaremos una estructura para fijar el casquete, que se obtendrá mediante mastiles, cables colgados, etc., según la solución buscada.

Por otra parte, habrá que resolver la inevitable acumulación de tensiones en la tela alrededor del punto de cuelgue. La solución más sencilla consistirá en suplementar la tela base con nuevas hojas, correctamente unidas a aquélla, según la tensión que se produzca.

El otro tipo de soluciones para apoyos interiores será la relinga circular alrededor del punto de cuelgue. Dicha relinga podrá ser, de nuevo, rígida o flexible. Las rígidas constituyen simplemente un anillo metálico que sujeta el borde de la tela y que absorbe las tensiones que se acumulan en el punto de apoyo. Las flexibles necesitan el cuelgue desde varios puntos. En ambos casos se suele producir un "agujero» en la tela (el círculo interior a la
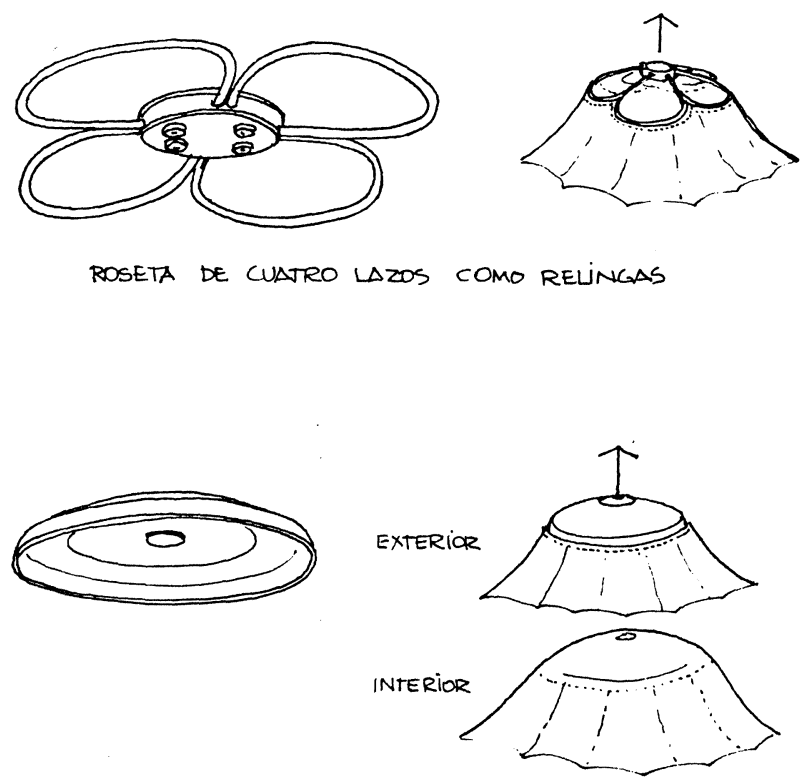

CASQUETE ESFERICO DE APOYO
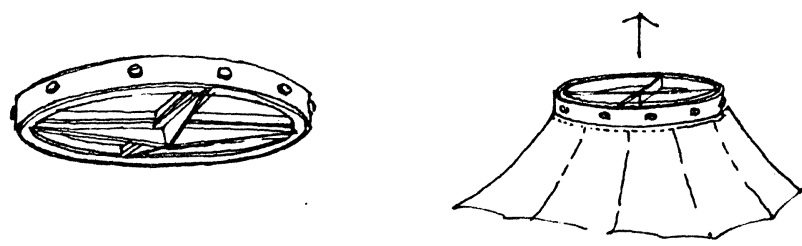

RELINGA RIGIDA CIRCULAR

Fig. 30.-Formas de anclaje puntual interior 

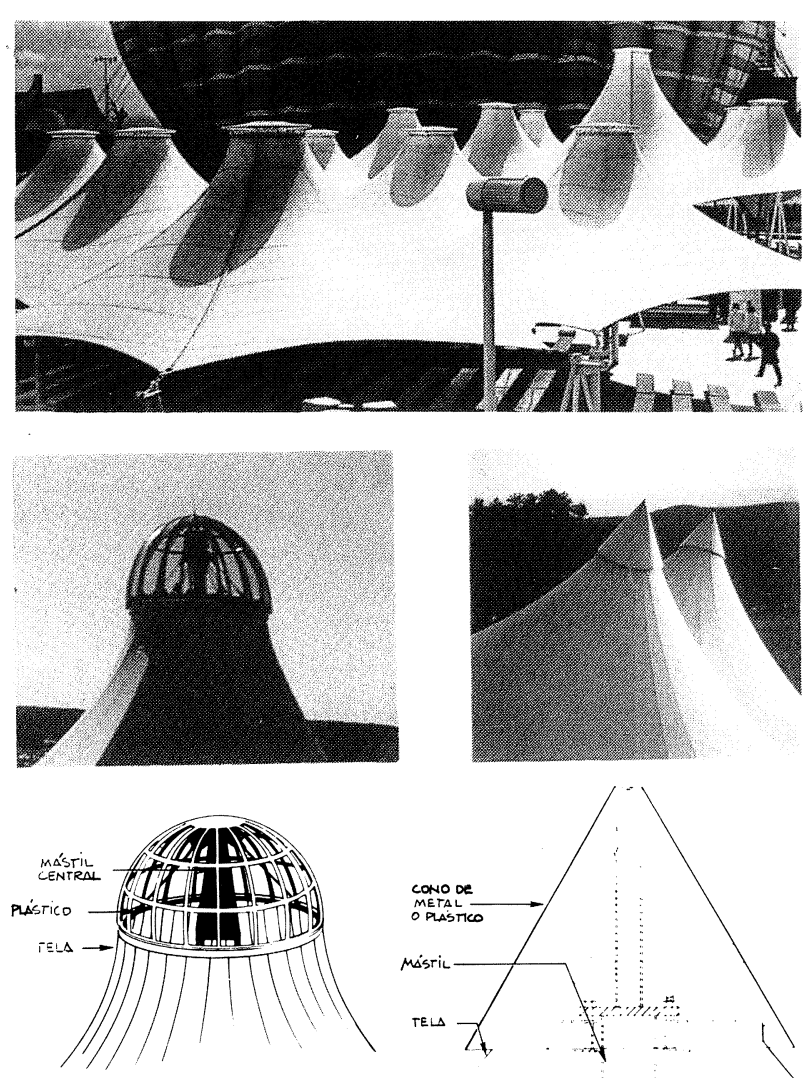

LUCERNARIO
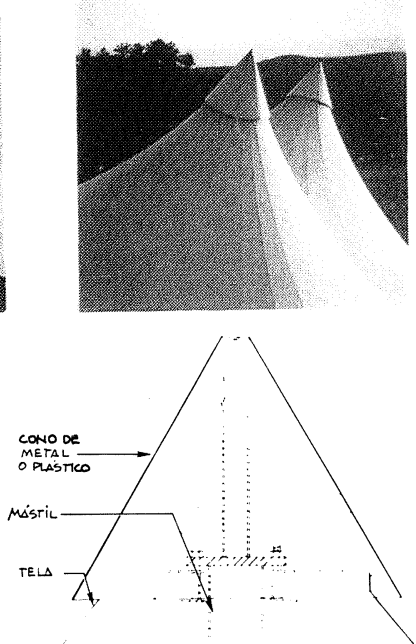

CAPERUZÓN

Fig. 31

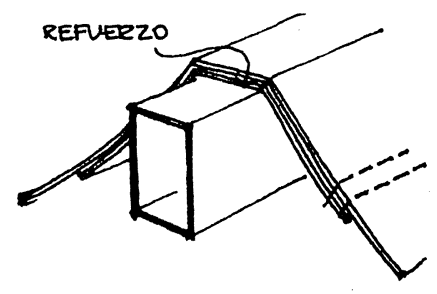

APOYO SIMPLE (CON REFUERZD)

Fig. 32.-Apoyo interior lineal.

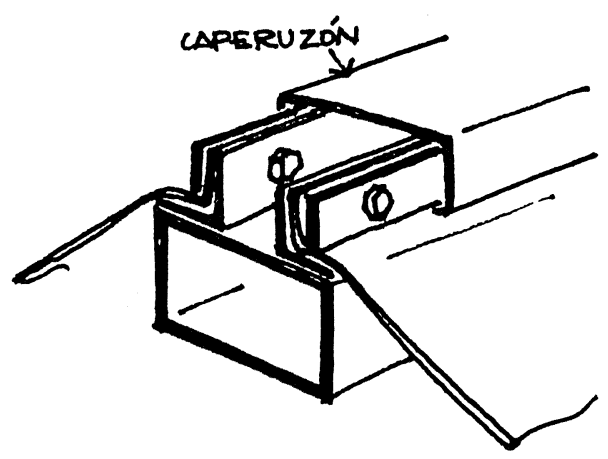

Fig. 33.-Apoyo doble relinga) que es necesario cubrir si queremos soluciones impermeables (Fig. 31). Por otra parte necesitaremos refuerzos en la tela pues, aunque la relinga absorba los que llegan al borde, en la superficie próxima a él existe también concentración de tensiones que puede requerir refuerzo en la tela. Como antes, se podrá resolver con hojas de tela adicionales perfectamente unidas a la original.

En el caso de apoyos interiores lineales la solución puede ser doble. Podemos simplemente "apoyar» la tela sobre la estructura (vigas o arcos) sin más que establecer un refuerzo en la línea de contacto, tanto para evitar rotura por roce, como para absorber la acumulación de tensiones. Podrá ser conveniente, además, establecer una sujeción de la tela a la estructura para evitar movimientos diferenciales peligrosos (Fig. 32).

Si la concentración de esfuerzos es importante o el tamaño de la cubierta lo requiere, podemos interrumpir la tela en la línea de apoyo y convertir ésta en dos anclajes perimetrales continuos, similares a los que veremos más adelante (Fig. 33) con lo que deberemos atender lo que alli expongamos.

Los anclajes exteriores son, en principio, más sencillos de resolver constructivamente, aunque la concentración de tensiones en ellos sea, evidentemente, mucho mayor que en los interiores, ya que la superficie textil queda muy reducida. Tiene normalmente formas triangulares. Por analogía, de nuevo, con las soluciones textiles de la navegación a vela, podemos hablar aqui de "puños», por lo menos cuando nos refiramos a los refuerzos que van a ser necesarios en estos puntos.

Cuando la relinga es flexible, no hay duda de que nos aparecerá una forma triangular, más o menos aguda, según la solución de la cubierta. En estos casos, si la relinga es interior y el ángulo es obtuso la solución más corriente será establecer un ollao en el punto de inflexión suficientemente reforzado. Además, habrá que reforzar el puño con hojas de tela unidas a la de base (estas hojas pueden ser múltiples y decrecientes para una mejor eficacia de la tela). Si, por el contrario, el ángulo es muy agudo y la tensión acumulada es grande, podremos llegar a sustituir el ollao por una pieza metálica que constituye propiamente un puño. Suele ser una pieza doble que abraza la tela por los dos lados y puede ir sujeta a la relinga para mayor efectividad (Fig. 34). Esta última solución requiere, también, como complemento, el refuerzo de la tela hasta donde sea necesario, según las tensiones previstas.

Si la relinga es exterior, podemos realizar el anclaje directamente a ésta, lo cual será fácil si el ángulo es obtuso. Si el ángulo es muy agudo, podrá ser conveniente, de nuevo, reforzar el puño con alguna pieza metálica que abrace la relinga (Fig. 35). En cualquier caso, conviene proteger la relinga en el punto de anclaje con alguna pieza especial y en todos ellos no debemos olvidar el refuerzo de la tela alrededor del puño, de la misma forma que veiamos en el punto anterior, pues al fin y al cabo el esfuerzo de la relinga se transmite a la tela que tiene que ser capaz de soportarlo. 


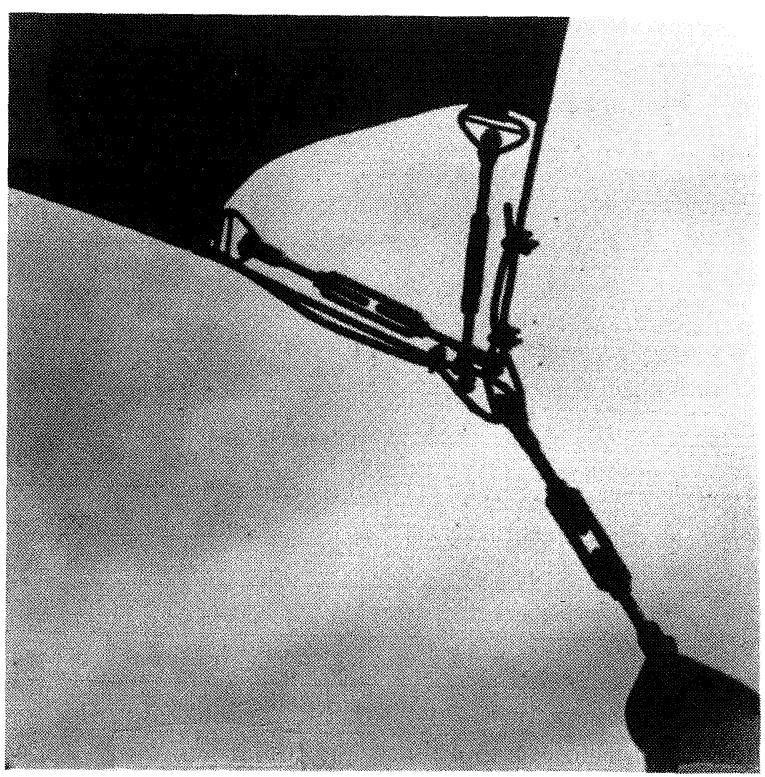

Puño con relinga interior y tensores.

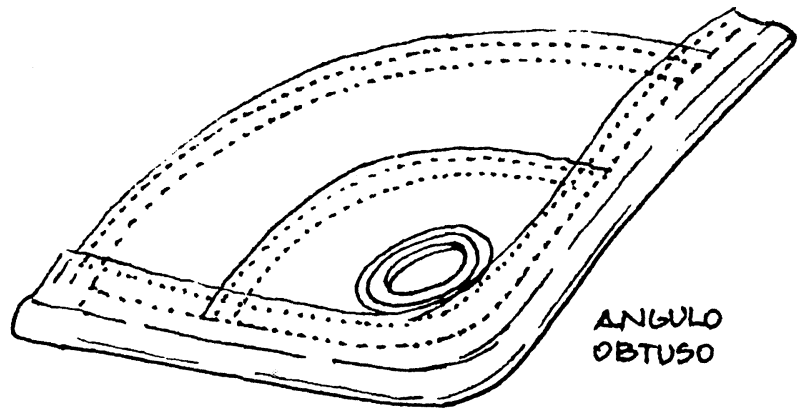

Relinga interior. Puños.

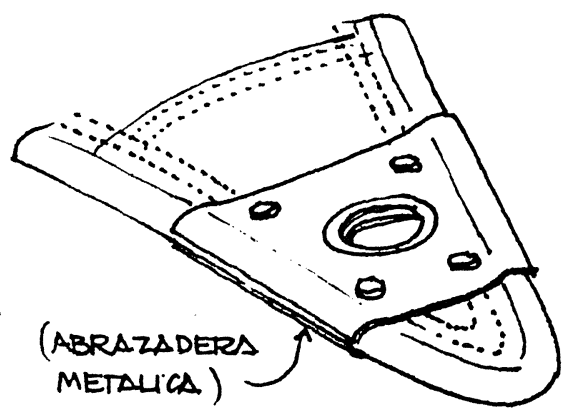

Fig. 34

Con relinga rígida, es difícil que aparezcan puños triangulares, por lo que las soluciones son menos comprometidas. En efecto, este tipo de relinga es adecuada para bordes rectos o con grandes radios de curvatura y cuando aparece una inflexión, la propia relinga constituye un puño reforzado. Los anclajes, por tanto, se limitan a la propia relinga y apenas afectan a la tela ya que la rigidez de aquélla hace que las tensiones le lleguen de un modo muy uniforme y repartido. Sólo cuando exista un cambio de dirección (un ángulo) podrá ser necesario el refuerzo de la tela (Fig. 36). La única diferencia en el anclaje po-
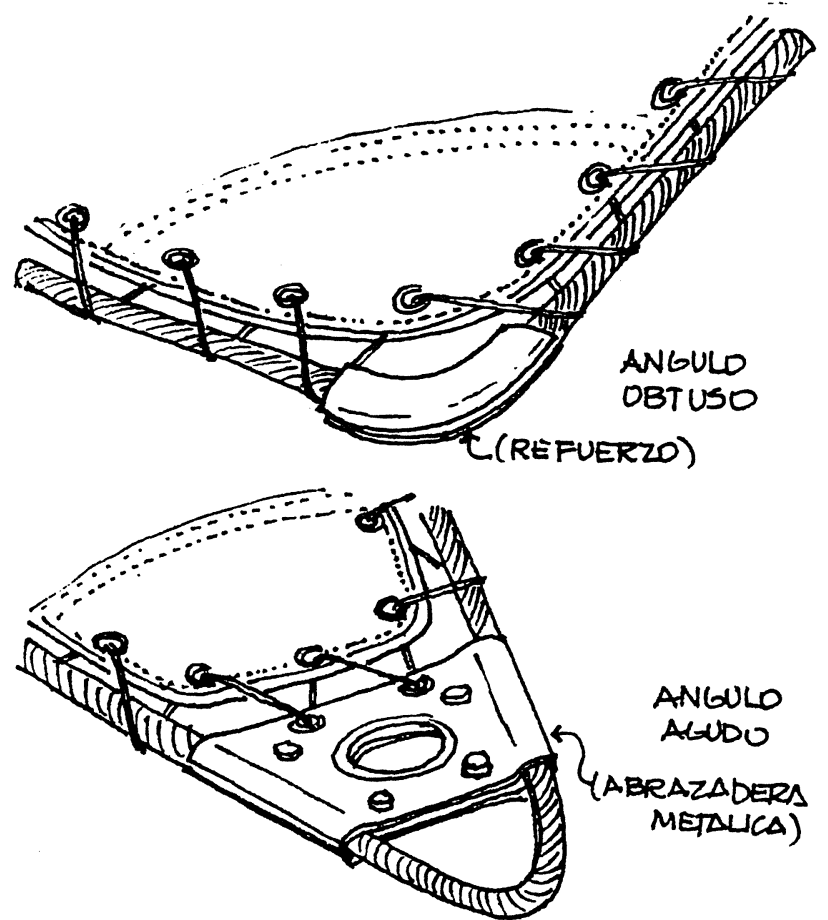

Fig. 35.-Puños con relinga exterior.

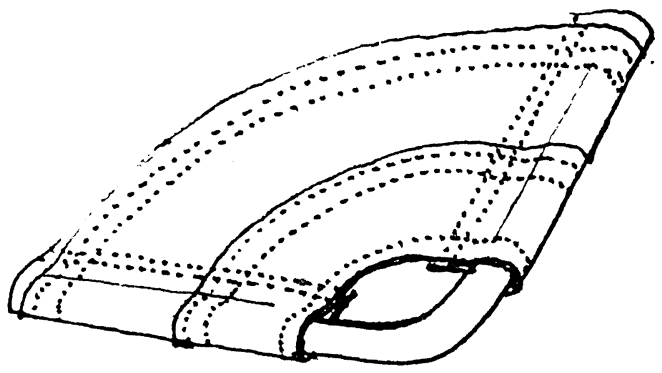

Fig. 36.-Puño con relinga rígida.

drá aparecer según la relinga sea interior o exterior y dependerá de cada caso.

Por último, el anclaje perimetral continuo es asimilable a la relinga rígida exterior, pues consiste en una estructura lineal a la que se sujeta la tela de un modo continuo, que puede ser, bien mediante ollaos y acordonado, bien mediante prensado del borde de la tela contra la estructura con la ayuda de un perfil metálico atornillado a ésta (Fig. 37).

Hasta aquí los anclajes que se refieren a la tela propiamente dicha. Pero en muchos de ellos, y sobre todo en los puntuales, los anclajes vistos hasta ahora son simplemente "intermedios» pues se realizan a una estructura auxiliar que, a su vez, tiene que estar anclada a una estructura definitiva o al mismo terreno, ya que esta «estructura auxiliar» suele tener unas características de ligereza y movilidad que la hacen inestable de por sí.

En efecto, si el anclaje puntual es interior, se relizará, normalmente, sobre un mástil. Este podría ser rígido y 


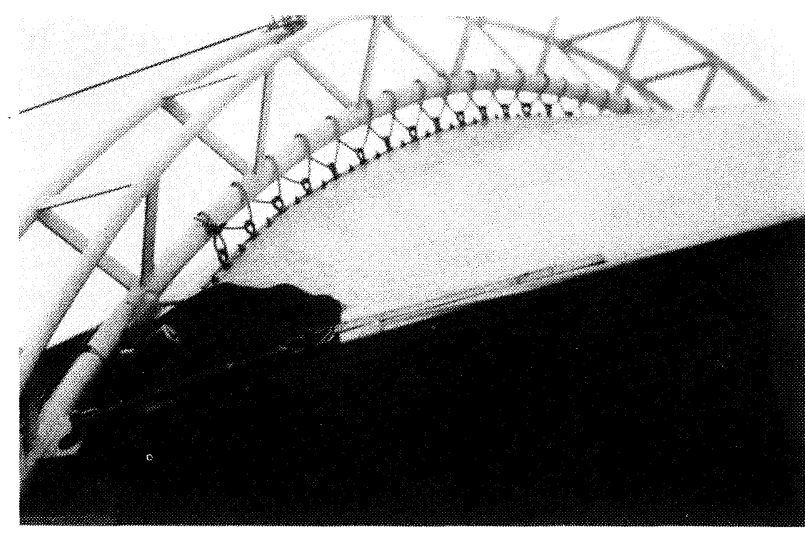

Anclaje continuo, perimetral e intermedio.

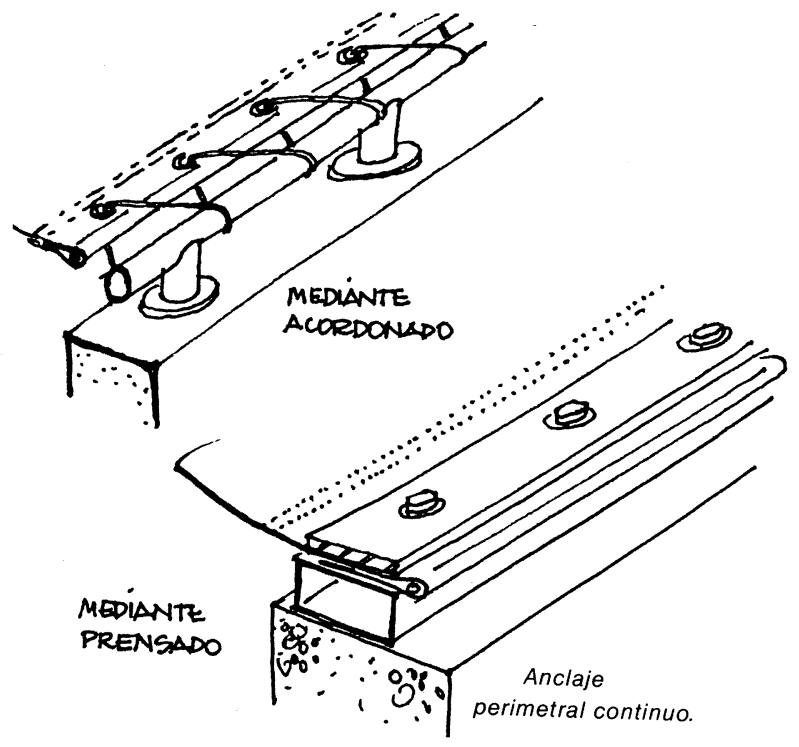

Fig. 37.

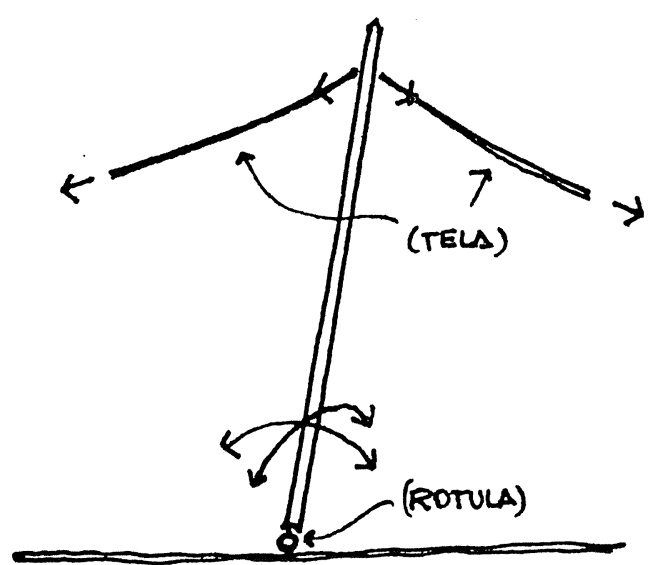

Fig. 38.-Mástil interior estable.

estar empotrado en su base, pero en el siguiente apartado veremos los inconvenientes que esto puede aportar al funcionamiento tensional del conjunto de la cubierta, por lo que usaremos preferentemente la solución articulada. Sin entrar en las diferentes soluciones constructivas de esta articulación, que corresponde a los problemas generales constructivos de estructuras lineales, si cabe mencionar que dicha articulación debe ser posible en todas las direcciones, por lo que nos encontramos ante una "rótula». La estabilidad del mástil, por otra parte, estará asegurada por la propia tela que lo mantiene en tensión en todas las direcciones $\mathrm{y}$, por tanto, en situación de estabilidad (Fig. 38).

Si se trata de un anclaje puntual exterior, la gama de posibilidades es algo más amplia. Si se trata de un mástil, podemos anclar la tela a la cabeza del mismo de un modo fijo, tensándola por lo menos en dos direcciones de sentido opuesto para conferirle estabilidad, resolviendo su base mediante una rótula (Fig. 39). Se puede intentar eliminar esta rótula, o, cuanto menos, disminuir su actuación, haciendo un tipo de cabeza de mástil «pasante» en la que los cables que lo anclan son los mismos que se enganchan a la tela, deslizándose por encima del mástil mediante canales o ruedas. Todo ello puede ir combinado por un sistema de muelles recuperadores en el anclaje de los cables del mástil al suelo, que, a su vez, pueden estar directamente sujetos a los cables o a través de una polea (Fig. 40). Este conjunto de posibilidades se tendrá que combinar, según veremos, de acuerdo con la solución elegida y el estado de cargas que se prevea.

Si el anclaje se realiza a un punto de una estructura fija, bastará con introducir un elemento recuperador de la tensión, que puede ser, de nuevo, un muelle, o un simple tensor manual que permite irse adaptando la tensión a la estructura según el estado de cargas sobre la tela (Fig. 41).

En el caso de apoyos lineales, las soluciones son asimilables a las anteriores. Cuando el apoyo lo constituye un pórtico (arco, dintel, etc.) éste tendrá que transmitir los esfuerzos al terreno $\mathrm{y}$, por tanto, lo podemos considerar como un mástil. En este caso, si es interior, resolveremos sus apoyos como articulaciones (en este caso, no tienen sentido las rótulas y bastará permitir la articulación en un plano perpendicular al del pórtico). Su estabilidad la garantizará la propia tela (Fig. 42). Si es un pórtico exterior, podremos también articularlo por su base, anclándolo mediante cables en el sentido opuesto al de la tensión de la tela. No será lógico, en este caso, hacer pasantes los cables de anclaje como en los mástiles puntuales. En cualquier caso, estas soluciones lineales, permiten también ir a apoyos rígidos y definitivos directamente (la tela se ancla directamente al terreno o a una estructura rígida) por lo que, en todo caso, lo único que podrá ser necesario, según el estado tensional, será introducir unos elementos recuperadores de la tensión (muelles o similares).

En el próximo apartado comentaremos algo más estas soluciones.

\subsection{Diseño y ejecución}

Hemos visto en el punto anterior algunos de los aspectos técnicos tanto de la tecnologia textil como de la constructiva, que condicionan el diseño y el montaje de las cu- 


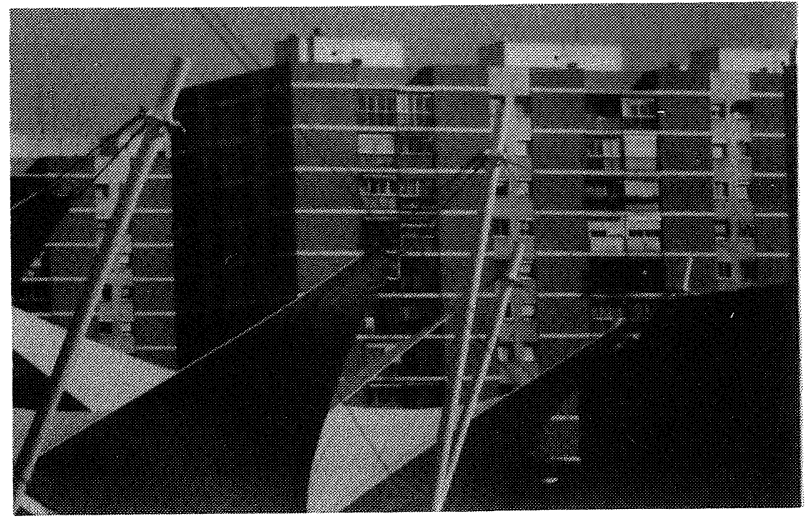

Anclaje de mástil exterior (fijo).

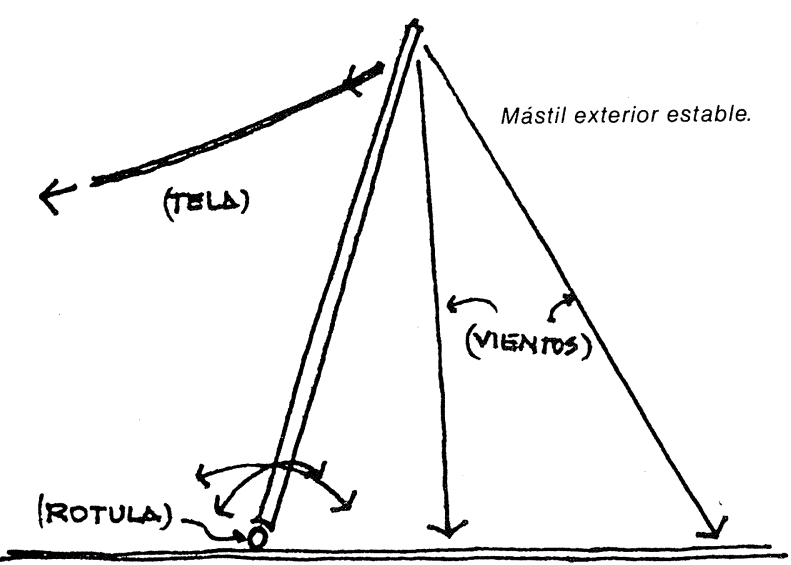

Fig. 39.

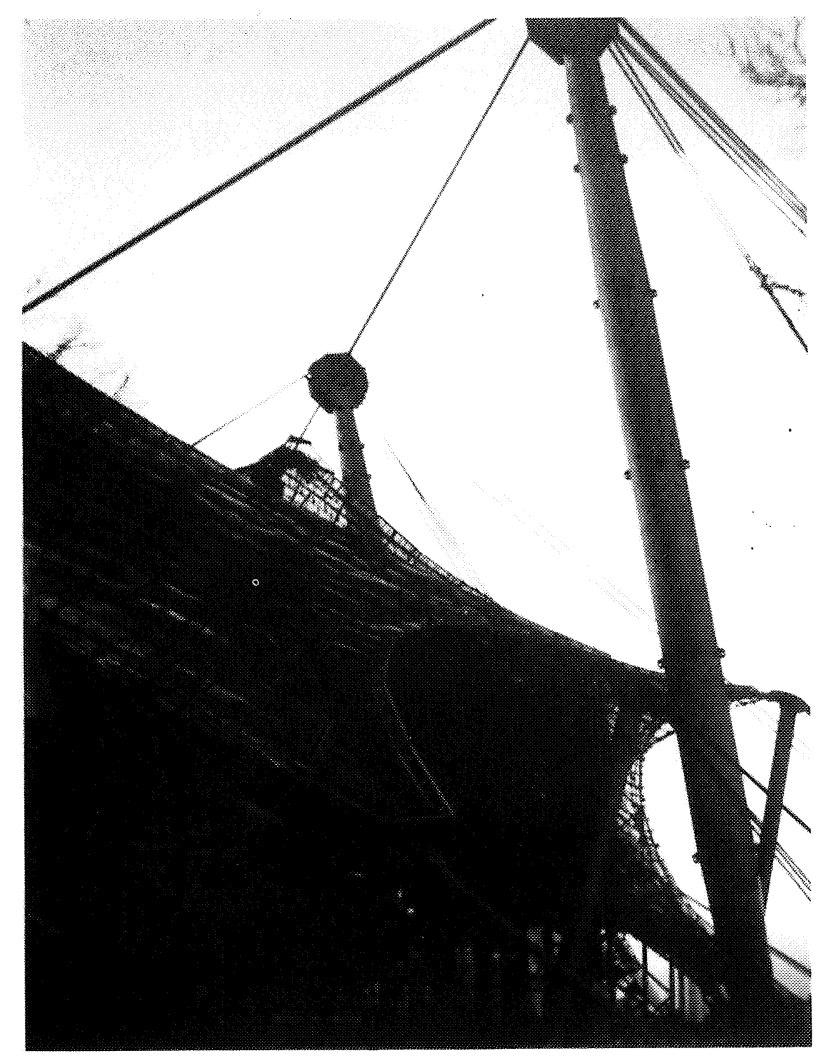

Fig. 40.-Anclaje de mástil exterior (móvil).

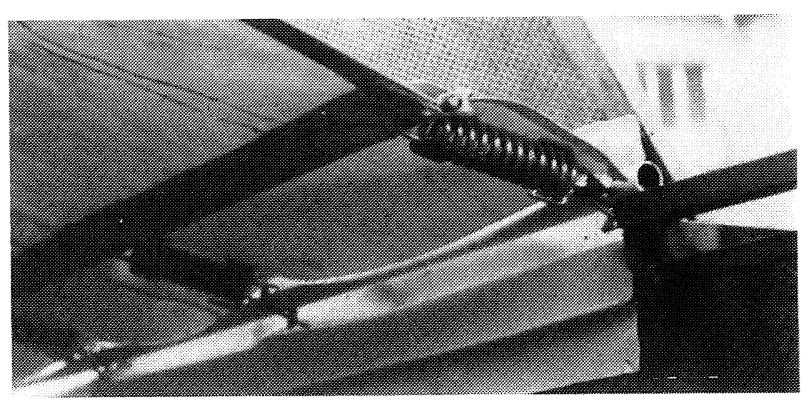

Anclaje con muelle.

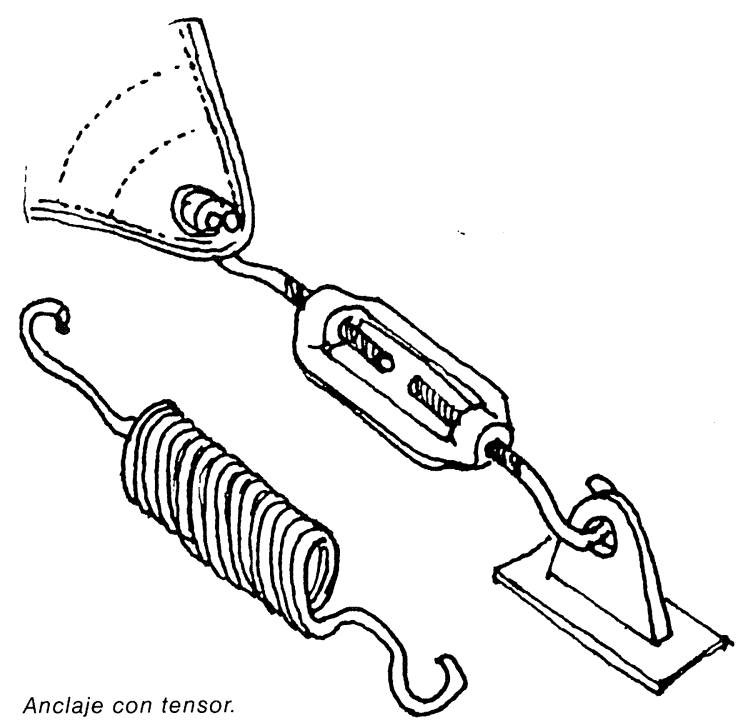

Fig. 41.

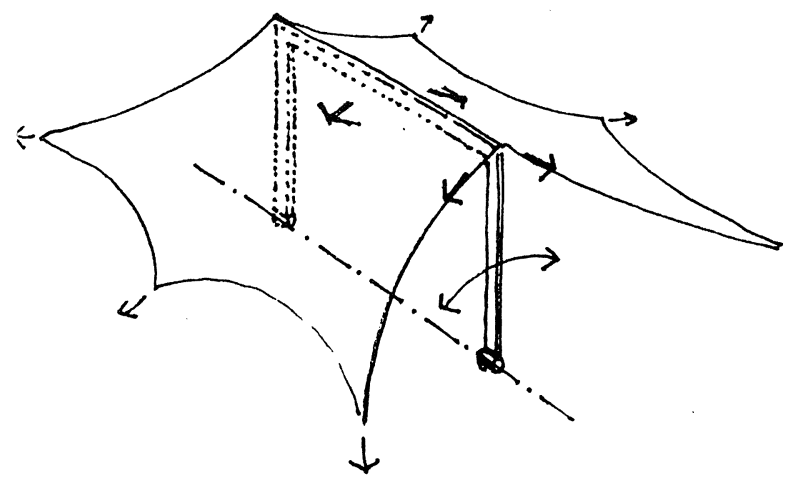

Fig. 42.-Pórtico interior estable.

biertas de tela colgada. Anteriormente habíamos visto los fundamentos, tando funcionales como tecnológicos, que soportaban el uso de este tipo de soluciones. Con ello, podemos considerar que tenemos los conocimientos básicos para una primera aproximación a este tipo de Arquitectura. Nos queda, pues, lanzarnos al proceso de diseño y ejecución de estas cubiertas, lo que podemos hacer analizando los diferentes pasos del mismo que deberemos dar para alcanzar una solución final aceptable desde todos los puntos de vista, funcional, técnico, estético, es decir arquitectónicamente aceptable. Al estudiar cada uno de estos pasos trataremos de incorporar y resu- 
mir los diferentes conocimientos que tenemos hasta ahora, en base a las páginas anteriores, lo que nos ayudará a recordar y a coordinar.

Podemos considerar tres grandes pasos en el proceso: diseño, confección y transporte-montaje. Veamos cada una de ellas.

\subsubsection{Diseño}

Diseñar algo es, básicamente, resolver un problema en el que se conjugan el objeto que queremos obtener y los condicionantes de todo tipo que sobre él van a actuar. La solución del problema arquitectónico, aunque es única, puede alcanzarse por cuatro enfoques del objetivo que se persigue, a saber, el enfoque funcional, la FUNCION, el formal, la FORMA, el comportamiento estructural, la ESTRUCTURA y la solución tecnológica, la TECNICA CONSTRUCTIVA. Estos cuatro enfoques pueden suponer y suponen de hecho, cuatro tipos de diseños (funcional, formal, estructural y constructivo) que deben estar interrelacionados entre sí, aunque a veces (demasiadas) resultan independientes e incluso contradictorios.

Si consideramos las cubiertas de tela como Arquitectura, tal como afirmamos al principio, su proceso de diseño participará de ese esquema. En él nos podemos basar para analizarlo.

\section{Solución funcional}

Deberemos preguntarnos, en primer lugar, cuál va a ser el uso de la cubierta y dónde va a estar situada. Según ello deberemos decidir entre los siguientes conjuntos de alternativas:

- Abierta-cerrada.

- Integral-parcial.

- Efecto invernadero-efecto sombrilla-alternativo.

- Transparente-opaca.

- Aislante-poco aislante (a la temperatura o al sonido). - Fija-móvil.

Los cinco primeros se refieren al tipo de ambiente que queremos lograr en el interior. El último a su uso en el tiempo.

El ambiente interior tendrá, en cualquier caso, unos condicionamientos inherentes al tipo de solución, de los que ya hemos hablado algo al principio de este trabajo. Será un ambiente básicamente poco aislado y luminoso, por lo que buscar condiciones interiores muy concretas, sobre todo cuando el ambiente exterior sea extremo, será inútil o muy dificil. Así pues, deberemos utilizar estas soluciones para ambientes interiores poco exigentes en temperatura pero con necesidades amplias de iluminación, sobre todo durante el dia. Son los típicos espacios públicos de grandes dimensiones donde se desarrolle una actividad física importante o donde se permanezca en unas condiciones de vestido similares a las exteriores. También se- rán útiles para almacenes y talleres industriales por las mismas razones.

En cualquier caso, y una vez conocidas las caracteristicas del ambiente interior deseado, podremos mejorar las aislantes del propio material, tal como vimos en el apartado correspondiente, o jugar con el diseño para obtener los mencionados efectos invernadero o sombrilla, según sea el exterior cálido o frío o estemos en época de invierno o de verano. Incluso podremos diseñar soluciones flexibles y alternativas, que nos permitan mantener el efecto correspondiente adecuado a la época y a las condiciones climáticas (por ejemplo, una cubierta que, mediante los necesarios artilugios mecánicos, actúe como invernadero en invierno, cerrando la posible ventilación, y de sombrilla en verano, abriéndcse y dejando pasar el aire) la combinación de soluciones mecánicas con soluciones textiles nos permitirán el juego de efectos necesarios en cada caso (Fig. 43).

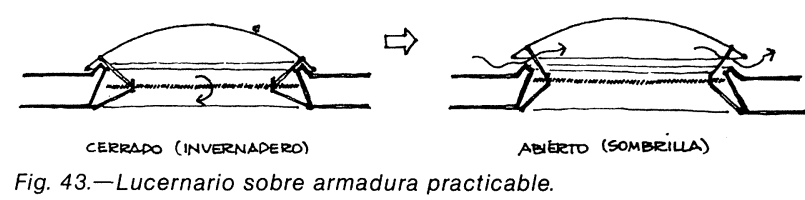

También podremos emplear este tipo de artilugios cuando queramos que la cubierta textil sea de «quita y pon» ya que en su colocación deberemos obtener las tensiones necesarias, lo que exigía mecanismos especiales. En este sentido son conocidas algunas soluciones alemanas en las que unos motores eléctricos corriendo a lo largo de unos cables son los que permiten plegar y desplegar la tela, sometiéndola a tensión. Más adelante comentaremos la incidencia que tiene la posibilidad de plegar la tela periódicamente en las características mecánicas de la misma y, por tanto, en su confección (Fig. 44).

\section{Solución formal}

En el apartado 2.3 hemos visto las posibilidades formales básicas de este tipo de soluciones textiles. Su selección para cada caso concreto dependerá de dos factores básicos: la planta que va a cubrir y el entorno en el que se asienta.

La planta, su forma y tamaño, junto con la diafanidad del espacio a obtener, condicionarán el sistema de anclaje y apoyo de la tela y, por tanto, su forma visual. No obstante, para cada planta hay multitud de formas, que se obtienen de las básicas que hemos visto anteriormente y que podemos agrupar en:

a) Carpas (superficies con apoyos o anclajes centrales).

- Positivas (apoyos hacia arriba)

- Negativas (anclajes hacia abajo) - Simples

- Múltiples

- Puntuales (apoyos o anclajes - Combinadas por puntos)

- Lineales (apoyos o anclajes por lineas) 


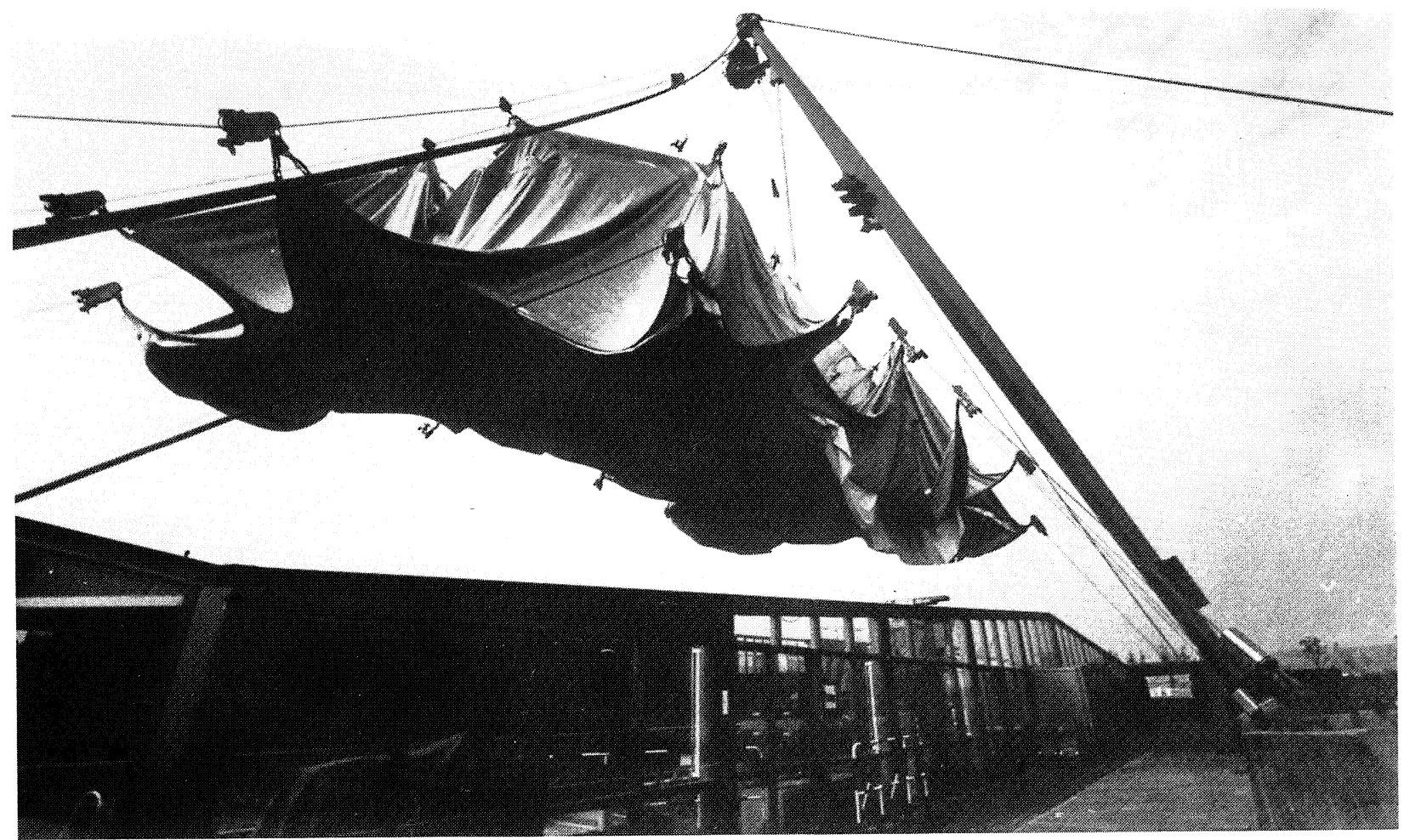

Fig. 44.-Cubierta plegable.

- En viga

- En arco

b) Toldos (superficies con anclajes perimetrales)

- Cilíndricos.

- Paraboloides hiperbólicos.

- Combinaciones.

El entorno nos condicionará la silueta de la cubierta cuando ésta cobre importancia desde alguna alineación visual. En este sentido, deberemos considerar que con las telas colgadas podemos obtener dos tipos de formas: puntiagudas y romas. Las primeras las obtendremos con las cargas y, sobre todo, cuando éstas tengan apoyos puntuales interiores. Las segundas, se obtendrán, por lo general, cuando empleemos apoyos perimetrales, sobre todo lineales, pero también podemos alcanzarlas con apoyos lineales interiores, sobre todo cuando son apoyos curvos (en arco).

En cualquier caso, tanto la forma que alcancemos por la planta y la diafanidad del espacio interior, como la que obtengamos condicionada por el entorno, nos definirán el tipo de apoyos y anclajes de la tela y, por tanto, estarán influyendo en las soluciones estructurales y constructivas (vemos como cobra presencia la necesaria interrelación entre los cuatro aspectos de la solución al problema de diseño).

\section{Solución estructural}

De acuerdo con la forma tiene que alcanzarse la solución estructural, es decir, el concepto del funcionamiento estructural de la cubierta, incluidos sus apoyos y anclajes.
Para ello partimos del principio ya enunciado de la necesidad de permanencia de tensión en la tela para lograr su estabilidad. Dicha tensión se introduce, tal como hemos visto, por medio de sus apoyos y anclajes. Pero la cubierta, una vez tensionada, tiene que hacer frente a otras acciones exteriores de las que las más importantes son la nieve y el viento, y principalmente éste. Estas cargas aportarán una nueva tensión en la tela que repercutirá en apoyos y anclajes.

Todo ello condicionará, evidentemente, el cálculo y el dimensionamiento de secciones. Hay, pues, dos etapas en esta solución: la definición del funcionamiento estructural de la solución adoptada y el cálculo concreto de apoyos, anclajes y tela. La primera, la más importante será interdependiente con las soluciones funcional y formal de los apartados anteriores.

Para analizarla veamos primero los condicionantes que aportan las cargas enunciadas y después sus efectos en la solución.

La nieve constituye una carga vertical, perfectamente definida en la norma MV-101, que afecta, sobre todo, en las zonas frias y a las partes horizontales de la superficie de cubierta, introduciendo una mayor tensión en la tela y sus anclajes y apoyos. Habrá que comprobar, por tanto, que la tensión en la tela no sobrepase la máxima admisible, así como en sus bordes (relinga y puños) donde, como sabemos, se concentra (casos se han dado en los que la acumulación de nieve ha producido el rasgado a partir de puños mal diseñados).

Dado que al buscar curvatura y tensión en la tela se obtienen formas con inclinaciones importantes, la acumula- 
ción de la nieve no es tan fácil. No obstante es posible, por lo que habrá que considerarla en todas aquellas partes de la tela con pendiente inferior a $45^{\circ}(100 \%)$ por lo menos.

El viento introduce un estado de cargas mucho más complejo. También la norma MV-101 nos da la presión que supone el viento según la zona climática, el nivel de exposición y la inclinación de la superficie de la cubierta. No obstante, cuando ésta tiene formas geométricas complejas y, sobre todo, cuando es deformable ante el viento, el conocimiento del estado tensional debido a esta carga es muy dificil. En estos casos se convierte, de hecho, en la carga más importante, y el cálculo tensional gira alrededor del viento. Sin afán de entrar en el análisis matemático de este estado tensional, para lo que habria que recurrir a los métodos finitos de cálculo con un número muy elevado de variables y para el que, evidentemente, necesitamos de ordenadores y programas específicos, si podemos realizar una primera aproximación al comportamiento de estas cubiertas de telas ante el agente viento, lo que nos puede dar las pautas para vislumbrar la solución estructural de cada caso concreto.

Aunque ya hemos adelantado algo al hablar de los fundamentos tecnológicos, recordemos que el viento es una fuerza básicamente horizontal que, al chocar con un obstáculo, en este caso la tela de cubierta, se transforma en una presión o succión perpendicular a la superficie de la misma y uniforme en todos los puntos de igual geometria. Podemos considerar que la succión comienza a partir de una inclinación de $45^{\circ}$ (Fig. 45), por lo que en un principio, y amén de los cambios de dirección y remolinos que puedan producirse como consecuencia de diversos obstáculos o de la propia geometria de la cubierta, podremos conocer con relativa facilidad el estado de las cargas producidas por el viento. En cualquier caso, y para un conocimiento más preciso, podremos recurrir a ensayar una maqueta de la solución a escala en un túnel de viento. Es un recurso muy utilizado, sobre todo en el estudio de grandes cubiertas textiles.

Los diferentes esfuerzos del viento en un momento determinado (el inicial) deberán ser absorbidos por la cubierta iniciándose su estado tensional. En este caso, y dadas las características elásticas del material (la tela), la absorción del esfuerzo se realiza en dos pasos sucesivos. Se produce, en primer lugar, una deformación de la superficie, tanto dentro de su geometría como fuera de ella, es decir, alargándose hasta reducir la tensión a una nueva de equilibrio, por una parte, y cambiando su geometría hasta adquirir otra forma que recibe una carga distinta, por otra (Fig. 46). Una vez deformada la superficie a una nueva geometría, que podríamos llamar «de equilibrio», si sigue habiendo aumento de la tensión, ésta debe ser absorbida por la capacidad ante tracciones del propio material (la tela) que lo hará hasta alcanzar la de rotura.

Ante esta previsión de actuación, en el diseño, además de dimensionar la tela y todos los anclajes para que sean capaces de absorber las tensiones que puedan alcanzarse en este segundo paso, al igual que haciamos ante la carga de nieve, deberemos pensar en la posibilidad de deformación de la cubierta para que se adapte en el primer paso a

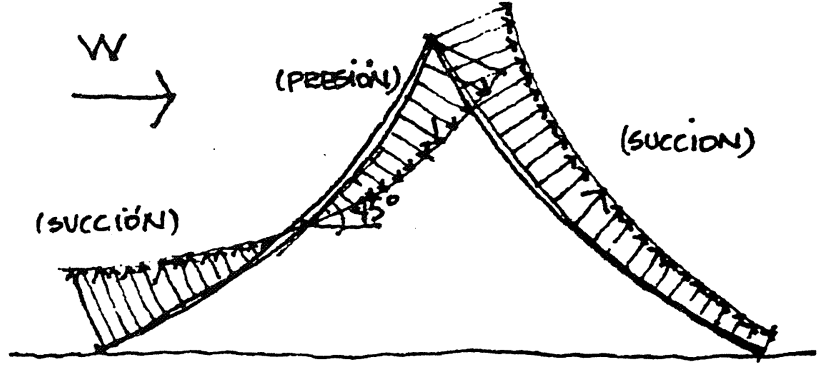

Fig. 45.-Efecto del viento.

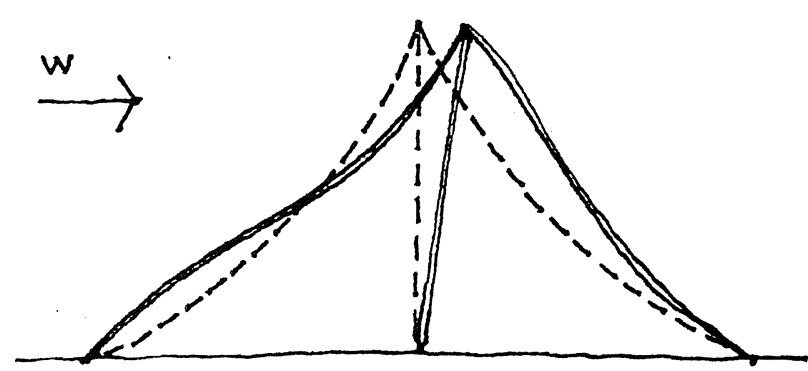

Fig. 46.-Deformación de equilibrio ante el viento.

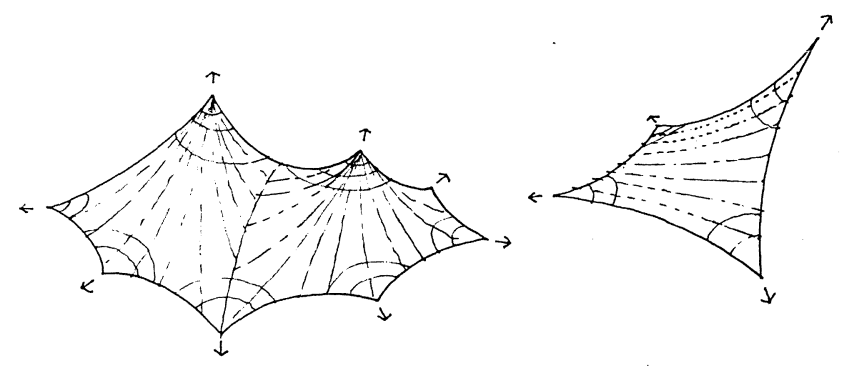

Fig. 47.-Refuerzos en puños (interferencia con patrones).

la forma que hemos llamado «de equilibrio». Para ello podemos jugar con la propia tela y su coeficiente de alargamiento que, como hemos visto, varía alrededor del $20 \%$. Pero esto puede no ser suficiente, por lo que tendremos que recurrir a otros mecanismos de los que ya se ha hablado en el apartado anterior y que permiten moverse a los apoyos y anclajes. Concretamente tenemos, por una parte, la articulación en rótula de las bases de los mástiles de apoyos centrales elevados, sean puntuales o lineales; por otra, los muelles y contrapesos en anclajes que deberán dimensionarse de acuerdo con la deformabilidad necesaria y la tensión esperada. Por otra parte, estos mecanismos nos permitirán mantener la tensión minima necesaria en la tela para su estabilidad, frente a cambios de signo en la presión del viento (de presión a succión), estabilidad, como sabemos, necesaria para el conjunto de la cubierta y la no aparición de arrugas.

En definitiva, pues, la solución estructural que alcancemos, que incluye sistemas de apoyo y anclaje, deberá estar en consonancia, no sólo con el estado de cargas y tensiones previsibles, sino también con la solución formal.

Una vez definida esta solución, entraremos en la fase de cálculo y dimensionamiento de cada una de las partes de la cubierta. Para ello, como ha quedado apuntado, debe- 
remos recurrir a métodos de cálculo sofisticados que se escapan del alcance de estas páginas. Las tensiones de tracción o compresión en soportes y anclajes nos darán las dimensiones resistentes necesarias, tanto de los mástiles (a compresión) como de los cables y anclajes (a tracción). En cuanto a la tela, la tensión previsible nos determinará la resistente de la tela, lo mismo que para las relingas. En estos casos, es importante considerar la concentración de tensiones en puños y cambios de superficie vista en apartados anteriores. Esta concentración exigirá mayor sección en estas zonas, lo que se puede resolver fácilmente mediante refuerzos sucesivos (Fig. 47) de un modo similar a como se resuelve en las velas de navegación. Sin embargo, no parece que ésta sea una práctica muy común en la Arquitectura textil, por lo menos hasta el momento, lo que puede deberse a los problemas de confección que implica en superficies tan grandes. El avance de la tecnología puede ir resolviendo este problema. Mientras, al no poder realizar este refuerzo adicional, no queda más remedio que utilizar una tela que sea capaz de resistir la tensión de los puntos más conflictivos, lo que implica una infrautilización en el resto de la superficie donde la tensión sea siempre menor.

\section{Solución Constructiva}

Una vez alcanzadas las soluciones funcional, formal y estructural, debemos complementarlas con la solución constructiva que nos marca la técnica concreta a utilizar en materiales y sistemas y que, inevitablemente, nos condiciona las tres anteriores. Para ello, recordemos los aspectos técnicos descritos en el apartado 2.4. En este punto, y de acuerdo con las soluciones anteriores, deberemos definir, por lo menos los siguientes aspectos: tela, confección, bordes, sistemas de apoyo y sistemas de anclaje.

La tela se elegirá en función de los siguientes condicionantes:

- Oferta de mercado y costes.

- Estado de tensiones previsibles.

- Necesidades de transparencia.

- Necesidades de acondicionamiento acústico.

- Necesidades de resistencia al fuego.

La confección deberá definir, tanto la descomposición de los patrones, que dependerá de las dimensiones de suministro de la tela, como el sistema de unión, lo que dependerá del tipo de tela y de las posibilidades de la confección de taller.

Los bordes de la tela (relingas y puños) se deberán diseñar no sólo en función de las posibilidades comerciales y del tipo de tela elegido, sino también del estado tensional previsto, así como del uso de la cubierta. Así, deberemos seleccionar entre relingas interiores (en dobladillo) o esteriores, y flexibles o rigidas; así como los tipos de puños, con refuerzo o sin él, y si éste puede ser con la propia tela, con la relinga o con piezas metálicas.
Los sistemas de apoyo y anclaje, por último, dependerán, sobre todo, de la solución estructural adoptada y del cálculo tensional, pero también del tipo de tela elegido, ya que, en definitiva, constituyen el nexo de unión entre una y otra.

\subsubsection{Confección y transporte}

El segundo gran paso, una vez finalizada la etapa de diseño, es la confección de la cubierta y su transporte al lugar de montaje. La primera se deberá realizar de acuerdo con el diseño constructivo $\mathrm{y}$, más concretamente, según la descomposición en patrones y el sistema de unión elegido. El segundo dependerá del tamaño total de la cubierta, por un lado, y de su carácter de permanencia, por otro, ya que si la cubierta es definitiva, su montaje y transporte tienen lugar una sola vez, por lo que parte de la confección puede desarrollarse en obra (uniones de patrones cuando son pegadas o soldadas) mientras que si es provisional y recuperable, su montaje es múltiple y tiene que considerar su desmontaje, por lo que no resulta conveniente dejar parte de la confección para el montaje, sino desarrollarla toda en taller.

Todo ello tiene una incidencia evidente en la fase de diseño, sobre todo en lo que se refiere a la solución constructiva. En efecto, la confección, por una parte, está condicionada - y condiciona - a la solución constructiva, tanto en tipo de tela, como en patrones, como en tipo de unión. El transporte, por otra, depende y condiciona, enormemente a la solución estructural y a la formal, ya que la tela, para ser transportada, tiene que doblarse con el fin de reducir su tamaño. La posibilidad de su doblado o «empaquetamiento» dependerá de la forma geométrica de la superficie de la tela y podrá condicionarla, sobre todo si la cubierta tiene que ser recuperable. Otras veces podrá forzar a descomponer la superficie total en sectores independientes para su más fácil confección y montaje, lo que introducirá uniones o sistemas de apoyo entre ellos que afectan a la solución estructural. Por último, el hecho de la repetitividad del montaje y desmontaje, por su tipo de uso temporal, implica unas características especiales en la tela (fibra y recubrimiento) que faciliten estas operaciones y no introduzcan grietas en su superficie.

En definitiva, esta fase del proceso deberá, como las otras, tenerse en cuenta desde el principio para considerar sus condicionantes (y resolverlos) desde la fase de diseño.

\subsubsection{Montaje}

También esta última fase del proceso puede introducir sus condicionantes que afectan a la fase de diseño y que deberán ser considerados desde el principio. Estos se refieren tanto al sitio donde va a estar localizada la cubierta como a su solución estructural y tecnológica. Veamos los más importantes. 
Tanto si la solución es fija como si es temporal, en el montaje hay que conseguir, por lo menos, los siguientes objetivos:

- Facilidad de montaje, lo que supone una manejabilidad adecuada de los tramos de tela que se monten a la vez y la posibilidad de su adecuada sujeción a la estructura soporte hasta obtener los apoyos y anclajes previstos en el diseño para su correcta función.

- Introducción de la tensión minima necesaria para la estabilidad de la tela, lo que puede ser conflictivo, sobre todo cuando la tela se coloca por tramos.

- Obtención de la forma final prevista, sin aparición de arrugas, y obtención de la función prevista en diseño, resolviendo todos los condicionantes funcionales que sean del caso.

El primero de los condicionantes, la facilidad de montaje, es importante siempre, pero sobre todo en los casos de soluciones temporales y recuperables, en los que la operación se realiza de una manera periódica. Evidentemente, ello implica disponer de los accesorios imprescindibles (grúas, andamios, etc.) siempre que ello sea posible en la localización prevista. En ocasiones, el tipo de montaje puede condicionar el resto de la solución, cuando éste sea muy especial o se deba realizar en condiciones específicas (casos de refugios de montaña, albergues provisionales para catástrofes, etc., donde la rapidez y la falta de medios suelen ser importantes).

En cuanto a la introducción de la tensión previa, sabemos que es primordial en todos los casos en que la tela actúe como estructura y queramos obtener una estabilidad inicial y ausencia de arrugas. Dependerá de todo el funcionamiento estructural previsto, de sus cargas y tensiones, así como de la estabilidad de conjunto que queramos alcanzar. Dicha tensión puede variar desde los $5 \mathrm{~kg} /$ $\mathrm{cm}^{2}$ que se utilizó en la cubierta del «Florida Festival» en Orlando, donde el conjunto es bastante móvil por el tipo de estructura utilizado (apoyos centrales con mástiles articulados en su base) lo que le obliga a importantes movimientos y, por tanto, a variaciones de tensión en la tela, por lo que no era importante tenerla excesivamente tensa desde el principio, hasta los $75 \mathrm{~kg} / \mathrm{cm}^{2}$ en la cubierta del aeropuerto Jah, en Jeddah, donde la solución estructural es mucho más rigida, los movimientos de la tela y las variaciones de su tensión, menores, $\mathrm{y}$, por tanto, la tensión inicial puede subir. (En definitiva, en soluciones estructurales «blandas» la tensión inicial será pequeña $-<10$ $\mathrm{kg} / \mathrm{cm}^{2}$ - mientras que en las «rígidas» la tensión de montaje será mayor).
Pero la aplicación de esta tensión no es sólo importante para la estabilidad final, sino que condiciona el montaje, ya que exige establecer unos puntos fijos, durante el mismo, desde donde se pueda aplicar. Si el tramo de tela que montamos a la vez va sujeto directamente a la estructura soporte, la aplicación de la tensión es relativamente fácil mediante gatos hidráulicos, motores eléctricos o simples tensores mecánicos. Pero, si por su tamaño y características formales, la cubierta se debe descomponer en tramos que van unidos unos a otros, en su montaje la introducción de la tensión se complica ya que cada tramo introduce tensión en el anterior y recibe tensión del siguiente. En estos casos, habrá que recurrir a diversos artilugios mecánicos que permitan mantener la tensión de un modo provisional a los tramos hasta que se haya colocado todo el conjunto, maxime cuando la tensión inicial sea alta por tratarse de una solución de las que hemos llamado «rígidas».

Como ejemplo ilustrativo cabe mencionar el caso del ya citado aeropuerto Jah en el que este aspecto era importante al ser la tensión inicial elevada. Como quiera que la solución consistía en tiendas unidas entre sí, se procedió a montar las tiendas en el suelo (unir las tiendas entre si) antes de someterlas a tensión, y después, el conjunto de las 21 tiendas que constituían unidad independiente, se izaban a la vez sometiéndolas a la tensión inicial de 75 $\mathrm{kg} / \mathrm{cm}^{2}$.

Por último, la obtención de la forma y la función final prevista es el objetivo básico de todo el proceso y dependerá del adecuado diseño, tanto de la confección, por un lado, como de la estructura, por otro. La sorpresa de no obtener la superficie prevista, una vez montada, puede ser muy desagradable.

No conviene terminar este apartado sin hacer una breve mención al mantenimiento. El mantenimiento es fundamental en toda edificación debido a su inevitable uso; también la Arquitectura textil requiere de ese cuidado y, por usar un tipo de materiales más nuevo y, quizá débil, el cuidado cobra importancia especial.

Con respecto a la tela, el fabricante deberá indicar el tipo de mantenimiento adecuado para la duración prevista e, incluso, garantizada. En cualquier caso, siempre será importante una limpieza periódica de la superficie exterior, sobre todo cuando la lluvia natural no sea suficiente.

Con respecto a la estructura soporte y a todos los complementos metálicos o de otro tipo que sean necesarios, pueden ser de aplicación las recomendaciones generales de mantenimiento (limpieza, protección, etc.) según el material de que se trate y su localización.

$$
\text { is 论弥 }
$$

